Article

\title{
Concept of Designing Thermal Condition Monitoring System with ZigBee/GSM Communication Link for Distributed Energy Resources Network in Rural and Remote Applications
}

\author{
Emmanuel Kobina Payne ${ }^{1, *}$, Shulin $\mathrm{Lu}^{2}$, Qian Wang ${ }^{1, *}$ and Licheng $\mathrm{Wu}^{1}$ \\ 1 School of Energy and Power Engineering, Jiangsu University, Zhenjiang 212013, China; \\ wulicheng@ujs.edu.cn \\ 2 College of Energy Engineering, Zhejiang University, Hangzhou 310027, China; 21860020@zju.edu.cn \\ * Correspondence: mypaynegl@yahoo.com (E.K.P.); qwang@ujs.edu.cn (Q.W.); \\ Tel.: +86-186-5284-1697 (E.K.P.); +86-139-1280-2056 (Q.W.)
}

Received: 29 April 2019; Accepted: 16 June 2019; Published: 20 June 2019

\begin{abstract}
Monitoring the thermal behavior of distributed energy resources (DERs) network explores the dualism between thermal effects and electrical power flow. This paper proposes a design concept that monitors thermal conditions of DER grids, using ZigBee/GSM wireless sensor networks (WSNs) for real-time monitoring in rural and remote areas. The concept seeks to improve upon existing designs by integrating composite functions. The functions comprise temperature conditions monitoring, data acquisition, and wireless data transmission including data storage and abnormal conditions alert/notification for control solutions. Thus, the concept determines the thermal impact on the DERs integrated network. WSNs with temperature sensors LM35 are utilized to complement ZigBee and Global System for Mobile Communications (GSM) technologies as a communication assisted link. Temperatures are measured from solar Photovoltaic PV modules, wind turbine, distribution cables, protection control units, and energy storage facilities. The ATMEGA328P microcontroller is assigned for signal and control processing. The circuit performance is coordinated and displayed on an LCD screen for normal conditions, whereas abnormal scenarios communicate through an alert/notification by GSM Short Message Service (SMS) protocol. The development analysis was performed through algorithm and circuit simulations. Proteus software was used for circuit design. Both the algorithm and circuit analysis passed the assigned simulation stages.
\end{abstract}

Keywords: distributed energy resources; thermal condition monitoring; wireless sensor networks; ZigBee/GSM communications

\section{Introduction}

There is no argument that temperature monitoring and thermal effect control are required for electrical applications. Operating temperature is significant in many electrical components' performance including distributed energy resource (DER) networks. The temperature measurements of the integrated DERs system impacts performance immensely. Although many available applications predict temperature scenarios, this paper opens another technology concept to determine uneven temperature indications. The existing schemes used approaches in which the system experiences latency in capability and with high maintenance cost. The proposed concept seeks to monitor the state of the thermal behavior in remote and rural areas of the distributed power grid. It utilizes wireless sensor networks (WSNs) for real-time online applications. It explores ZigBee and GSM communication techniques for network operations. The complex nature of the DERs grid with different components 
and material characteristics increases the power demand and hence causes severe thermal problems to the network. It then results in a reduced power quality [1,2]. Thermal behavior monitoring is relevant in electrical distribution networks for the performance of current, voltage, real power, and reactive power. It also influences the operation of protection and control systems.

The thermal conditions scenario demands the DERs grid to have prompt system monitoring and potential self-healing schemes to address the development of faults using WSNs [2]. Discussions in [3,4] consent to the monitoring and reliable strategies of distributed power grid adapting to online monitoring to enhance system performance and integrity. The consent reflects the criteria for analyzing DER grid operations, hence involving Information Technology (IT) and Operational Technology (OT). The technological advancement for merging IT and OT improves data acquisition for system performance of DERs as smart grid [4]. Moreover, in [4,5] system planning, operation, and protection control, OT promotes efficiency in DER networks. The above discussions support online thermal conditions monitoring and controlling of the grid operations to achieve optimum performance. It is also consistent with the assertions in [3] which advocate that the DERs grid improvement cannot adequately be achieved without real-time and online conditions monitoring of components performance. Furthermore, active integration of the DERs network requires an innovative communication assisted link. It enhances data acquisition for control solutions and involves WSNs for intelligent interoperability systems in emerging smart grid applications [4,6,7]. ZigBee/GSM communication links have evolved as standard technology that addresses the needs of most remote monitoring, control, and sensor network applications [8,9].

Additionally, it aids in evaluating the DERs grid operational resilience and performance characteristics per the data input and output response rates [10]. Thus, the proposed concept aims at providing information about the grid component performance through temperature analysis and processing. The concept could also assist in quantifying energy loss trends due to abnormal temperature thresholds captured data; for example, solar PV high temperature [11], and thermal effects resulting from harmonics $[10,12]$. The data obtained from the monitoring can be useful for early assessment of system degradation [10]. The issuing of prompt alert/notification defines control actions, while also impacting functional defects analysis. Besides, it will also be applicable for evaluating the unpredictable weather occurrences from solar PV modules and wind turbine performances. In [13], yearly temperature performance characteristics were done on solar PV cells during normal operation. Similar exercises have been performed on cables, wind turbines, protection systems, and batteries, including inverters in Section 2. The cursory analyses of such studies are discussed in the respective areas of Section 2. Per the significance of thermal effect concerning the integration of the DERs grid, expertise is encouraged to develop effective, low cost, and viable monitoring systems for small and medium scale Distributed Generations (DGs) to ensure optimal performance [13].

Thus, the wireless communication network is an emerging technology that integrates WSNs and mobile computing with transducers to perform sensor platform topology $[14,15]$. The integration of computing techniques and Radio Frequency (RF) has dominant features. The design concept explores LM35 temperature sensors to measure the thermal conditions of the system and archives them at the Data Management Unit (DMU) of the Distribution Management System (DMS). The performance provides the state assessment of DERs behavior in order to respond timely, should abnormal conditions occur [16]. Therefore, the reliability of the entire system is assured in times of critical network situations. The thermal effect when not monitored restricts the system's power delivery, as temperature profile rises excessively. It then reaches a critical state of condition, destroying the distribution network components $[17,18]$. It further affects system configuration performance when the demand side operates beyond the threshold capacity.

The scope of the study is to develop a concept to synthesize the thermal behavior of DERs integrated network comprising solar PV panels, wind turbine compartment, distribution cable lines, protection control components, and storage batteries with inverters. The concept seeks to leverage system real-time monitoring of temperature profiles. It uses sensor operating techniques and software 
computing with ZigBee communication link and also transmits abnormality through GSM protocol. Should the temperature experience out of range threshold, the system sends an SMS notification to the DMU. The alert details the characteristics of the unit elements in such a condition. The design configuration involves wireless sensor monitoring, data acquisition, and transmission data storage with abnormal threshold conditions alert for activation of control solutions. The alert activation for control solutions could be configured to regulate system intelligence to actuate control schemes applicable for remedial actions during abnormal temperature scenarios. The control schemes may be configured to control system functions for solar PV panels cooling in the case of extreme temperature effect and for cleaning dirt accumulation on the panels. Again, the control scheme can be assigned to operate the cooling system in the protection control unit to solve high-temperature issues. Further, the scheme functions can be programmed to activate reactive power injection should the thermal impact affect power delivery. The design concept has been developed and simulated with Proteus 7.9.

The concept design was coded and analyzed in two parts for simulations in the algorithm and circuit development. The algorithm simulation passed a four stages test and the circuit development was successful in the assigned simulations. The exercise randomly selected temperature values for the test threshold configuration and system operation measuring data. The outcome of the performance of the simulation is captured and presented in Section 4. The ZigBee communication link operates per the Institute of Electrical and Electronic Engineers (IEEE) standard protocol 802.15.4. The paper is arranged, in the following order: Section 2, discusses the importance of thermal condition monitoring, Section 3, handles the development of thermal condition monitoring system, Section 4 deals with the system configuration and performance analysis, and Section 5 concludes the study.

\section{Importance of Thermal Condition Monitoring}

\subsection{Attributes of Thermal Condition Monitoring}

Renewable energy distributed generation development is challenged with enormous constraints for successful integration. Irregular generation capacity thresholds or high demand side load may increase the nominal system power beyond set points. This condition may exceed the thermal impact limit. The network components of intrinsic characteristics may also contribute to the DERs thermal constraints. The temperature profiles of the subsystems significantly contribute to the existence and life expectancy of the DERs grid. Moreover, adverse thermal conditions violate the protection of functioning mechanisms in the network configuration. Proper use of the monitoring system for thermal behavior aids in controlling the conditions of the network components. The achievement of the DERs status is possible by online and real-time data profiling and prompt maintenance scheme development. The maintenance strategies may be in a form to control generation sources temperature, control schemes to minimize harmonics development, and load management at the demand side. Knowing the thermal condition of the DERs network is an essential and reliable indication of an integrated distributed power grid status. The sudden increase in temperature of the system may indicate system overloading, development of harmonics, deprived passive or active cooling of generation resources, ineffective lubrication, and possibly severe weather fronts $[19,20]$. The need for improving the DERs integrated grid thermal conditions monitoring motivates the concept of measuring system components status. The literature indicates that aspects of distributed renewable power generation predicaments are from thermal constraints during operations. The constraints cause events involving materials heat characteristics and the components configuration failures. These increase temperature thresholds due to the behavior of the components influence on a system with thermal impact performance. The development again causes system thermal effect, which leads to power generation and delivery impairments. Further, the thermal effect affects electric power consumers of the required energy needed for reliable performance $[19,21,22]$. Photovoltaic components made from semiconductor materials, which have the properties of photoconductivity, suffer from thermal effect. The electrical conductivity of the PV cell is affected by the exposure to electromagnetic radiation 
(sun/light). The semiconductor material releases electrons which are present between its conductor and insulation domains. The generated tension for the release of the electrons between semiconductor domain regions of " $\mathrm{P}$ " and " $\mathrm{N}$ " causes electric power production from solar PV cells. However, recombination occurs within the semiconductor material during which a free electron could bounce back to become an atom. This recombining electron does not contribute to the production of electrical current. It develops incident solar energy, which creates heat as wasted energy. The incident solar energy of the PV panel creates convection and radiated heats, which anticipate being cooled by the air current. Should the temperature of the cooling air not be active, the wasted energy seeks to be absorbed by the PV cells and develops opposing characteristics to current. The same scenario happens in the power electronics inverters. This phenomenon then impedes effective power collected and affects the energy conversion efficiency of the solar PV panel and power electronics inverters performance $[10,12,23,24]$.

Additionally, the higher proportion of the solar irradiance absorbed by the PV module does not commensurate as electric energy; conversely, it creates an increase in the temperature of the PV module, hence reducing the PV efficiency. Moreover, the temperature of the PV module is influenced by numerous factors such as heat dissipation of the material, the module packaging criteria, and the PV module installation procedures. Again, the speed of the wind and ambient temperature as a cooling medium impacts the absorption of solar irradiance on the modules [13]. The band gap of the solar cell is also affected if the temperature of the PV module increases. It increases the short-circuit current (SC) at about $0.1 \% /{ }^{\circ} \mathrm{C}$ and causes a reduction in open-circuit voltage (OC) of about $2 \mathrm{mV} /{ }^{\circ} \mathrm{C}$ [11]. These assertions seek to confirm that the PV modules are strongly affected by the incident solar temperature. Thus, the temperature of the module is a critical measured variable in order to predict the performance of the PV system for DERs integrated grid [11,25]. Our proposed design concept has unique composite functions for temperature conditions monitoring, data acquisition, and wireless data transmission with data storage. It further explores the potentials of ZigBee/GSM and WSNs communication links for abnormal condition alert and notifications for control solutions.

\subsection{Solar PV Panels}

The actual operation of solar PV modules, according to numerous characterized experiments, prove that electrical efficiency decreases significantly with the increase in the temperature of photovoltaic cells when exposed to the sunlight $[11,13,26,27]$. The loss of electrical power can be enormous if there are no provisions for cooling on the module, especially in tropical regions. When sunlight falls on the solar PV cells, part of the radiation converts into electrical energy, but others reflect or convert to thermal energies [28]. The electrical energy may be stored in a battery for later use or transferred directly to the grid, but the thermal energy available on the surface of the module still exists only to be recovered by the air blowing as a cooling medium.

In situations where the air temperature is high, the cooling becomes ineffective, and thus creates an adverse thermal effect on the PV modules. In developing power efficiency for solar PV installation, the measured data should include solar irradiation, ambient temperature, and wind speeds to prove the power generation commensurate with the efficacy of module surface cooling by the air velocity $[27,28]$. The temperatures that are considered critical in the installation of the solar PV module are the cell design temperature and the temperature of the air flow. With these two temperatures, an evaluation of the electrical and thermal performance of the PV modules can be assured, regarding efficiency and power delivery. The increase in PV cell temperature has the effect of reducing the power efficiency proportionally when the reaction of air-flow temperature increases, hence the need to monitor thermal effects against power delivery efficiency $[11,13,27-30]$.

\subsection{Wind Turbine Rotatory System}

Challenging environmental factors combined with high turbulent operating conditions place considerable pressure on wind turbines and result in the failure rate of components. It is vital to strictly 
observe the wind turbine operations. Proper uses of condition monitoring to detect the early stage events minimize the thermal impacts and fatigue development [31]. Temperature is a critical and readily measured indicator for the health status of wind turbine components. Since wind turbines deal with moving parts, the concern for condition monitoring should be with the generator temperature for real-time measurements. Other variables that have a close relationship with the generator compartment temperature should be included especially in tropical areas where the temperatures may escalate beyond the threshold levels [32,33].

The real-time online temperature measuring variables emphasize the importance of monitoring thermal status in wind turbines. Power generated from wind turbines bears significant influence on the temperature of the generator. When the output power is high, the generator stator current becomes very large, resulting in the generator temperature increasing. The impact affects the insulation cooling of the generator [19,34]. The condition demands critical attention because the temperature of the generator cooling air (GAT) impacts the stator cooling. It then affects the generator stator winding temperature (GT) when cooling is ineffective, affecting the components of rotatory compartment therein. Ambient temperature has a high impact on the local temperature when the wind turbine experiences changes in the short term (for example, from a day to the night) and in the longer term (weeks to months). There is also development due to passing weather fronts in the systems and seasons. The ambient temperature must be considered explicitly during the design and installation of the system/plant. Moreover, changes due to the fluctuating weather heads create significant turbulence on the turbine aerodynamics and further develop friction loss [34]. The Nacelle temperature has a close relationship with the generator temperature and cannot be overlooked [34]. In particular, the electrical/electronic components located within the Nacelle could experience extremely high-temperature variations leading to inconsistent operational stresses or thermal fatigue. In order to maintain acceptable temperature levels inside the Nacelle and to efficiently control the thermal impact, it is necessary to have a real-time online condition monitoring system to send information promptly, hence our design concept.

\subsection{Distribution Cable Lines}

Thermal properties and mechanical stress of cables influence the capacity threshold of the DERs network [35]. These are basic fundamental parameters for monitoring the cables in the DERs grid. The direct instant measurements of such temperatures are often not reflective. The use of thermal capacity models combined with the measurement of causes of internal heat sources and external conditions have not helped in the past. The temperature limitations often constrain the capacity of cables in DERs grid because of the uncertainty in power variations. The network suffers this predicament due to the variable generation forms and variability in the demand side load. The temperature and environmental conditions that vary according to the weather pattern also influence fluctuations, contributing to the conductors' thermal problems. Per the factors mentioned above, conductors' thermal performance for load capacity cannot be static. Thus, this calls for prompt monitoring of the conductors' state of thermal behavior [34,36]. To improve on the conductor thermal impact, the cables for distributed networks should depend on real-time data measurements obtained from online monitoring. The real-time data will indicate the weather relations with ambient temperature and load conditions, particularly in the extreme wind velocity conditions [35]. The data then serves as a model for assumed homogeneous temperature distribution for the conductors. The model can be developed, as a state estimation algorithm for computing heat transfer of the line conductors.

The algorithm can then be used, for the effect of different temperature conditions transfer associated with cable temperature behaviors [35,37]. Again, mechanical stress or changes in physical conductor parameters affect the ohmic resistivity and thermal conductivity [20]. This effect is proved, by the heat balance of Equation (1):

$$
P_{J}+P_{S}=P_{C}+P_{R}
$$

where, $P_{J}=$ heat increase by Joules, $P_{S}=$ Solar heat (direct), $P_{C}=$ heat loss from convection, and $P_{R}=$ heat loss from radiation [20]. Therefore, the scenarios mentioned demands composite monitoring system 
to manage such impairments. For this reason, our proposed design concept seeks to resolve that. In the case of underground cables, the design concept resolves to the equivalent thermal circuit model (temperature $=$ heat $\times$ thermal resistivity) considering the effect of soil or Earth's concealment as a compensating factor [38]. The model of the underground cable scenario takes consideration of the heat transferred from the conductor through the thermal conduction and the thermal remanence in the insulation jacket and duct (if present). This includes the earth conditions as a result of soil temperature [38]. The model impacts on the sensor monitoring configuration for performance accuracy and threshold indication. The corresponding data and communication interface for the transmission and processing of signal applies to standard system protocols.

\subsection{Protection and Control Components}

The uses of electrical power protection and control device are strongly dependent on the method of operation and the maintenance conditions applicable [38,39]. The compositions of power devices include organic or inorganic insulation systems. The electric field intensity and partial discharges includes other electrical phenomena impact on its thermal performance. The temperature of protection components become an essential determining factor because it affects the properties of the electric system functioning. This poses significant aging factor when power actuating equipment operates beyond their threshold. Again, during the full and unstable load conditions, temperatures increase and cause material characteristics change due to stress on the components. Abnormal high sustained temperatures may also cause overheating of the protection control systems. Therefore, the performance becomes unreliable and causes a high degree of failures [39].

The issue of heat dissipation becomes worse when there are no adequate ventilation slots in the protection enclosures or compartment. It is also necessary to consider that additional power losses are caused by the switchgear actuation and the auxiliary functions due to thermal effects. The impact affects the performance of relays and other controlling components. The losses are caused by the load conditions and overheating of protection control systems, thus impact extremely on the operations and lifespan of the protection control equipment [40]. The thermal condition monitoring focuses on the temperature measurement of the protection devices and the transformer insulation cooling system (coolant or oil) for real-time online measurement of thermal behaviors.

\subsection{Storage Batteries}

The need for continuous monitoring of batteries temperature and thermal control becomes paramount as operating temperatures affect many energy storage devices when they operate out of their thermal threshold [41]. Many applications require the battery cells or super-chargers to be stacked to meet the required voltage or power levels to perform efficiently. Uneven temperatures continue to impact the life of the battery operations, hence the need for the temperature monitoring system for rapid measurements. The thermal condition monitoring system should promptly indicate the measurements beyond the operational setup margins. For this purpose, real-time online measurements and performance of state estimation are essential. The temperature sensors are supposed to be in place for readily monitoring and transmitting thermal behaviors [42,43]. Cell performance may change abruptly with temperature fluctuations due to batteries exposure to sudden temperature changes.

The situation can result in limited performance, which is attributed to the change in cell chemistry, especially at low temperatures [42]. Such a scenario ascribes to the electrochemical characteristics of the active chemicals used in the cell and for which the nominal voltage of a galvanic cell sets. The terminal voltage always associates with the load currents and internal resistance of the cell's properties. These are influenced by the temperature of the cell charge state and the age of the cell [43]. Repetitive charging at low temperatures can cause the accumulation of internal pressure of cells, causing electrolyte leakage by high-temperature conditions. As a result, it is ideal for critical monitoring of the batteries for temperature variations. The DERs system assigned for the grid voltage coordination and power level regulation should be monitored against unfavorable situations. Batteries dedicated 
for such applications need to be in order to keep them at the specified temperatures, above the freezing point, and at the predetermined thermal threshold through real-time online monitoring system [43].

\section{Development of Thermal Condition Monitoring System}

\subsection{Design Concept Relevance to DERs Integrated Grid}

The emerging power grid control is experiencing innovations in intelligence in order to deal with increasingly diversified challenges, involving the environment, security, and infrastructure. The application of smart grid is realized with proactive usage of technology advancement in the areas of monitoring, regulation, and controlling through OT to address the challenges [44]. Resilient communication links serve as essential characteristics in the integration of DERs grid for independent and uninterrupted operations. In achieving such an objective, the proposed concept resolves to utilize ZigBee communication assisted link for condition monitoring and data acquisition including alert notifications. It integrates the WSNs and DERs grid to achieve network efficiency. The ZigBee communication link uses spread-spectrum communication techniques to complement smart grid technology in homes and industrial automation [10,11,45-47].

On the contrary, the traditional methods are saddled with signal transmission latency and high capital installation and maintenance costs. The proposed concept comes with composite characteristics such as temperature condition monitoring, data acquisition, wireless data transmission spectrum, and data storage with abnormal condition alerts or notifications. The alerts could easily be configured for control solutions. Nevertheless, the concept is envisaged to be less costly in terms of installation and maintenance. Moreover, control solutions could be proposed to involve many activation functions. Additionally, it would be ideal for rural and remote areas deployment [10-12,48-50]. It is significant to note that current carrying capacity and maximum permissible temperature are two variables that influence the design and operation of distributed grid control configurations. The current carrying capacity determines the thermal capacity according to multiple factors such as the temperature limit, safety resistance clearance of critical components, and the system voltage limit. The thermal effect is influenced by the heat loss radiative force. It correlates with the difference in temperatures between the equipment in operation and the cooling medium. The maximum current carrying capacity and operating temperature provide relevant information of the DERs grid failure prognosis through real-time condition monitoring [49-51]. A literature review of numerous communication links support ZigBee/GSM WSNs as an active link for monitoring and coordinating thermal effects $[9,24,44,45,52,53]$.

\subsection{Overview of the Communication Link}

Most existing network thermal conditions monitoring are models of the medium and high voltage grid systems. It is essential to note that those networks have different compositions from the renewable distributed power generation network. Therefore, it is unique to have a suitable communication assisted link for thermal condition monitoring with functions relating to the dynamics of renewable power generation network. The ability to manage thermal behavior efficiently in the distributed network depends on the prompt nature of the grid communication network and configuration strategies, as the operation of the communication link promptly impacts system performance. The communication link composes the channel conveying the signal and the terminal hardware components transmitting or receiving signal.

Communication channels used for monitoring thermal conditions of existing power networks have their functions attached to the established infrastructures. Such communication links use network configuration channel involving power line carrier, microwave, and fiber optics. With the increasing concern for the reliability of the DERs network, thermal condition monitoring scheme demands communication links to have advancement in characteristics. The DERs integrated grid differs from the conventional power network, usually having distance within short ranges with more connecting loads, which are subject to greater load variance and congestions. The distributed network requires a 
communication link to have the characteristics giving an assurance of reliable performance with low cost and low power consumption [22,54]. Review of available related works presents the strengths and weaknesses of communication links such as direct pilot wire, leased digital phone line, fiber optic cable, licensed radio, and spread-spectrum radio (in which ZigBee belongs). The consideration for the choice of a specific communication link includes the bandwidth and speed of signal transmission with security robustness $[22,54,55]$. However, priority begets the ZigBee link capabilities regarding the systems vast array of potentials for WSNs monitoring and controlling. The economical synthesis of the project targets in rural and remote areas focuses on the low cost of components and low power consumption. In appraising the communication link characteristics, it was an undeniable fact, the spread-spectrum radio and licensed radio channels share essential advantages with fiber optic channel as unique links. They have the lowest latency, dilation of signal, and are unaffected by the electrical transients or ground potential rise (GPR) associated with power system faults. They have good speed of communication channels, which depends on the channel's data rate, the size of the message, and the existence of dominancy in both ends terminal equipment. The same cannot be said of a leased phone line or a direct pilot wire, which may be out of service during a fault condition [21,56].

Routing the communication signal directly from the terminal equipment of the transmitter to the receiver avoids delay and this applies to the frequency of unlicensed radio bands of $900 \mathrm{MHz}$ and $2.4 \mathrm{GHz}$, including others from point-to-point spread radios which ZigBee WSNs affirms. The advancement in ZigBee application embraces an acceptable line of sight range depending on the configuration supports applicable [55]. Although the radio signal may experience interferences of co-existence of spectrum from $\mathrm{Wi}-\mathrm{Fi}$, spread-spectrum radio sets reasonable classification of signal protections across a wide frequency band. As a result, the link signal has security features to overcome interference when applied properly. Link signals on spread-spectrum have special characteristics of disallowing narrowband interference from intruding [55].

Invariably, fiber optic has the best attributes regarding communication links with numerous advantages and operational easiness. However, some drawbacks cause fiber optics to suffer beyond the technical performance. The reasons being that when buried it can inadvertently be excavated; trees may fall on them, especially in rural or remote applications. The cost of optical fiber repairs is overwhelmed by this outcome. In this regard, the use of spread-spectrum radio concept has been ensured, with the advantages that once the system gets installed there are no additional recurring costs, such as license fees or leasing and does not experience any physical breakdowns. There are modalities in place for signal improvement against Wi-Fi and other interferences; thus, the system reliability can be justified. Invariably, signal congestion can be controlled with appropriate communication techniques application [21,55-59]. Table 1 illustrates the types of ZigBee devices and characteristics in practice.

Table 1. ZigBee device characteristics comparison $[48,58,60]$.

\begin{tabular}{cccc}
\hline Characteristics. & XBee ZB & XBee-PRO 2B/C & XBee-PRO 868 \\
\hline Indoor Range & $40 \mathrm{~m}$ & $90 \mathrm{~m}$ & $550 \mathrm{~m}$ \\
Line-of-Sight Range & $120 \mathrm{~m}$ & $1.5 \mathrm{~km} / 3.2 \mathrm{~km}$ & $40 \mathrm{~km}$ \\
Radio Frequency Data Rate & $250 \mathrm{kbps}$ & $250 \mathrm{kbps}$ & $24 \mathrm{kbps}$ \\
Frequency & $2.4 \mathrm{GHz}$ & $2.4 \mathrm{GHz}$ & $868 \mathrm{MHz}$ \\
Transmit Power & $1.25 \mathrm{~mW} / 2 \mathrm{~mW}$ & $10 \mathrm{~mW} / 63 \mathrm{~mW}$ & $1 \mathrm{~mW} / 315 \mathrm{~mW}$ \\
Encryption & $128-\mathrm{bit} \mathrm{AES}$ & $128-\mathrm{bit} \mathrm{AES}$ & $128-\mathrm{bit} \mathrm{AES}$ \\
Transmit Current & $35 \mathrm{~mA} / 45 \mathrm{~mA}$ & $205 \mathrm{~mA} / 120 \mathrm{~mA}$ & $500 \mathrm{~mA}$ \\
Receive Current & $38 \mathrm{~mA} / 40 \mathrm{~mA}$ & $45-47 \mathrm{~mA}$ & $65 \mathrm{~mA}$ \\
Number Channels & 16 & 15 & 1 \\
Regions & Europe, Japan, Australia, & Europe, Japan, Australia, & Europe \\
\hline
\end{tabular}




\subsection{Overview of WSNs and Communication Links Characteristics}

Data transmission over cable systems and lines has been found to have high latency and are susceptible to several challenges which minimize their communication effectiveness. This has led to the development of new technologies for wireless network communication and optic based communication systems. However, in developing rural settings and remote areas optic fiber communication is not practically realistic due to its high cost vis-à-vis human linked breaks in sub-terrain activities. Wireless communication, though known to have marginal challenges in relation to weather conditions, is deemed to have a better yield when optimized through linked budgets. This logic informed the development of the proposed system to incorporate Wireless communication in the DERs grid monitoring management systems.

There are diverse wireless communication technologies for WSNs application in the commercial markets for different developments, namely home automation, control of agricultural applications, laboratory and experimental research works, and industrial intelligent monitoring and controls $[61,62]$. The WSNs application in emerging industrial intelligent monitoring and controls are gaining significance in most energy and power engineering industries and their performance are commendable in the promotion of operational technology [63]. These industrial WSNs are used for monitoring conditions of system performance in order to master the thresholds and operation controls status. The industrial WSNs in their application are mandated to comply with industrial standards and code of practice [63]. The standards emphasize uniformity in operations and adherence of security and safety practice. These characteristics are in accordance with IEC 61850, IEC 60870-5, ISA 100.11a, and IEEE 802.15.4 standards. Although the evolution of wireless communication technologies is envisaged, their application should propose relevance in the industrial wireless sensor network application where deemed possible for deployment.

The advancement in micro-electro-mechanical systems (MEMS) and digital electronics processing facilitates the development of less costly, low-power, and multifunctional WSNs sensor nodes for miniature sized systems and signal transmission in relatively acceptable distances. The collaborative effort of the WSNs evolution enables system operations to be autonomous, unattended, and adaptive to environment at reasonable cost as compared to traditional wired instrumentation and communication systems. With the said attributions, WSNs technologies propose to be prominent in industrial and automation development to enhance system operational performances. In view of this, the paper presents overview characteristics of wireless communication technologies applicable in practice of the DERs system applications $[57,62,64]$.

\subsubsection{Attribution of Emerging Wireless Communication Links}

Modern DERs grid integration monitoring and control requires communication between different components to enhance the reliability of grid functions. This demands a reliable range communication protocols for a guaranteed performance. The emergence of wireless communication technologies for distributed grid operation proposes various functioning characteristics with their pros and cons [65]. The concerns of wireless connection for DERs performance present comprehensive benefits with some drawbacks [66], which influence the general communication requirements of smart grid application deployment. WSNs are maturing technologically and in the practice of field applications for physical parameters and also intelligence to transmit signal wirelessly. These present measurement indications in their performance context for operational readiness [65,67]. They exhibit potentials of development in scientific and industrial communities, thus reinforcing the beliefs that new paradigm of sensing applications are gaining resiliency. Accordingly, the low-power wide-area network (LPWAN) has emerged as a WSN-based technology that adds to the wireless communication solutions [67]. Gradually, its addition seeks to enhance industrial wireless sensor applications and deployment.

Particularly, the technology is poised for much development concerning asset management in wide coverage areas of monitoring and controls for processing and production plants. It does propose to improve operation and performance reliability. This means the application could be 
useful to distributed energy systems in the context of operational technology for a smart grid concept. The main characteristics are its excellent long-range, low-power consumption, and reduced computation capacity $[65,68,69]$. Although cable-based networked communications are sometimes an infeasible resolution, however due to their complexity in installation and maintenance, their presence in industrial monitoring and controls are still being accommodated until they are completely phased out. In distributed energy systems with high penetration for renewables distributed generation units, connecting at different voltages and power levels make the evolution of wireless technology proposal significant in all performance [65-67]. This proposes a solution to performance assurance to overcome the operational deficiency as a result of cable breakdown and other lapses in variables indications.

The LPWAN encompasses group of technologies, allowing wide area communications at low cost points and reduced power consumption. LPWAN technologies have arisen in both licensed and unlicensed frequency band allocations, such as long range (LoRa), Sigfox, and Narrow band (NB)-IoT/LTE-M [67,70]. The NB-IoT and LTE-M are considered to be of inter-linked communication, per the spectra band. Amid the LPWAN applications, LoRa and NB-IoT/LTE are the most projecting ones, although they plainly exhibit different technical characteristics. LoRa can operate in both licensed and unlicensed bands however; there are limitations in some countries for acceptance due to signal performance hitches on the ISM band deployment. Unlike LoRa, an NB-IoT/LTE network deployment requires setup on existing cellular network $[69,70]$. This makes LoRa a more flexible solution than NB-IoT/LTE to meet the requirements of outlying decentralized network and reaching out to grass root levels where applicable. It is worthy to consider how LoRa is convincingly becoming the main actor in the current LPWAN scene, in deployable areas as it applications operates on an unlicensed spectrum below $1 \mathrm{GHz}$ and also supported by more world leading communication technology entities. From a technological viewpoint, LoRa offers a proprietary chirp spread spectrum (CSS) modulation to achieve greater communication ranges. LoRa has outstanding performance as compared to other modulation methods and has unique spread spectrum techniques, which deliver robustness against signal interference for long ranges and low signal-to-noise ratio for the receiver to be able to demodulate. LoRa is thus a suitable solution for systems that require a very long battery lifetime and reduced cost. Besides, its technical prowess, it suffers from less operational coverage in the rural and remotes areas due to low data rate and rare messages receipt acknowledgement $[67,69,70]$. Again, challenges on ISM spectrum application results as another disadvantage being identified when LoRa solutions are implemented, to operate intrinsically on an ISM band. Specifically, current international laws demand a stringent duty-cycle of $1 \%$; LoRa falls short of that. This means the radio channel does not occupy more than $36 \mathrm{~s}$ per hour. In reality, this value is denoted as the maximum transmission duty cycles (TDC) permissible by the nodes to operate in ISM channels [69].

In addition, LoRa consents to tuning of other physical transmission properties, such as the bandwidth and central frequency of the communication, hence the coding rate (CR). This impacts the ratio of the length of the packet and the error-correction code length. The transmission power and the spreading factor (SF) thus defines the symbol rate and chip rate. Higher SF values improve the sensitivity and range of communication at the detriment of increasing the over-the-air time of the packets, hence consuming more TDCs $[65,68,69]$. Furthermore, LoRa/LoRaWAN uses the adaptive data rate (ADR) algorithm in estimation of $C R$ and $S F$ parameters under specific channel mandate. Sigfox also belongs to the LPWAN group and is deployed on licensed network, thus performs well in its enactment territory but globally having challenges in operational expansion in relation to LoRa. The LPWAN characteristics are compared with ZigBee in the preceding subsections.

\subsubsection{Payload Data Rate and Scalability}

Numerous parameters could be used to evaluate the wireless network performances. The assessment expresses technical ideals of network configuration performance and reliability. The considered parameters deem to have the following characteristics to guarantee signal reliability $[64,67]$. Throughputs present quantity of data transmitted appropriately from the source to 
the node sink within a specific time mandates in (secs). The node rate is an indication of estimated data packets received effectively at the node gateway from the routing/coordinator scheme, which proves the received bits number with the total time of signal on transmission. The network performance is an accomplishment of all the nodes rates inferred in the data transmission. Besides, an end-to-end delay is equal to the time taken by the data packets to reach the destination nodes, hence called the packet delay. Consequently, good-put is considered as the data packets rate received functionally of the total transmitted data packets. The lost data packets rate does not take into account the retransmissions of signal during delays. Therefore, the good-put is evaluated as the expression of latency time, which is equal to the message creation time deducted from the message arrival times [69]. Service time represent the message life time from its creation by the transmitter until the positive acknowledgement of message reception. ZigBee uses CSMA/CA and GTS to impact on its real-time characteristics with extremely low duty-cycle of about $0.01 \%$. ZigBee is envisaged to contain about 65,000 nodes in application $[64,65,71,72]$.

Several techniques are under consideration to involve its deployment of efficient exploitation for WSNs channel diversity as well as in time and performance delivery. However, NB-IoT/LTE offers the advantage of very high scalability than Sigfox and LoRa. NB-IoT/LTE allows connectivity of up to 100,000 end devices per cell site on full deployment as compared to 50,000 nodes for cell site of both Sigfox and LoRa [69]. Whiles the NB-IoT/LTE also offers the advantage of maximum payload length but of limited access of transmission. LoRa, although second to NB LTE with multiple gateway layers receiving signals concurrently, thus causes signal collapse and delays. On the contrary, Sigfox proposes to have the lowest payload length, which puts limit on its utilization for perspective WSN applications that may need to transmit large data sizes on its link for industrial pruposes [68-70,73].

\subsubsection{Real-Time and Quality of Service Characteristics}

Although wireless communication infrastructure peculiarities impact relative countermeasures of signal propagation challenges, real-time applications are however feasible in its case of implementation. Real-time characteristics of WSNs require the sensor network techniques to provide mechanisms that guarantee certain level of quality of service (QoS). Whereas added objective functioning of the sensor network is to minimizing energy consumption. This presents a paradigm of schemes that delivers WSNs application-level QoS efficiently and charts the mandates to achieve network-layer metrics devoid of jitter and latency. Data delivery delay in WSNs present specific system design challenges and denies signal throughput $[64,67,72]$.

Real-time characteristics of a system prove relevant when even one deadline miss could have serious concerns of the network performance and reliability. Given the importance of having guarantees of deterministic signals, it is desirable to develop a centralized access protocol for real-time signal paradigm reasonably than a random access. The IEEE 802.15.4 and ZigBee deploy hybrid approach of centralized master/slave of Carrier Sense Multiple Access with Collision Avoidance (CSMA/CA) and PAN Coordinator (PC). This allocates up to seven (7) Guaranteed Time Slots (GTS), both probabilistic and deterministic real-time signal guarantees. This seeks to achieve a mandate exploiting the advantages of a centralized scheme with access to the channel regulation by a central node which permits the application of scheduling possible deterministic signal through performance during the phase called Contention Free Period (CFP) [71,74-76]

Sigfox and LoRa differ in application characteristics and frequency band unlike ZigBee which operates fully on ISM band. Besides, Sigfox and LoRa have limited access to some countries of application and of different communication protocols. Again, their capabilities are not that resilient to offer the same QoS provided by NB-IoT/LTE. Contrarily, the NB-IoT/LTE deployment is on licensed spectrum and LTE-based synchronous protocols have guarantee of very good QoS with high input and operational cost, which involve licensed LTE spectrum lease cost. Due to the QoS and cost tradeoff, the NB-IoT/LTE favors the applications that involve guaranteed quality of service (QoS) and of very high conscious security, whereas applications that do not have such features should 
consider LoRa or Sigfox [65,68-70]. Additionally, unlike Sigfox, LoRa offers class C features to also handle low-bidirectional latency at the expense of increased energy consumption. Consequently, for applications that are impervious to latency and do not involve large amount of data transmission, Sigfox and class-A of LoRa could be optionally considered. However, for applications that requires low latency and long range of star topology, NB-IoT/LTE and class-C LoRa are the better choices but with cost implications and low data rate [66-70].

\subsubsection{Deployment and Cost Implications}

Wireless communication offers low cost, high accuracy, and great flexibility solutions for wireless industrial energy monitoring platforms. The ZigBee module offers low power demand and low transmission costs, and it is proposed for systems where data exchanges between sensor nodes and the gateway frequently requires straightforward interface especially for rural and remote area application. This does not involve cloud-based interface and thus improves real-time characteristics. The cost of operation of ZigBee is very economical as its components are readily available and does not involve complicated developments skills $[64,69,74]$. The recently released NB-IoT/LTE specifications are still on rollout as a concept and hence not matured enough for industrial WSN applications in rural and remote areas [70]. Thus, additional time will be required for the network to be established. Although Sigfox and LoRa have passed the conceptual stage, they have limitations to be applied in full at rural and remote areas due to their cellular nature. Thus, they are still progressing under commercialization in limited countries and cities. LoRa has benefited from installation and operations currently in about 42 countries and Sigfox in 31 countries [69].

However, the deployments of LoRa and Sigfox in the world are still in deployment and strategizing. Several cost considerations need to be taken into account, such as spectrum cost for license, network/deployment cost, and device (base station installation) [69,70]. In general, flexibility and low-cost of scheme application abodes and facilitates the deployment of the WSNs solutions. This determines the drive to carry out a suitable design concept for the proposed system to monitor DERs grid integration conditions. In conclusion, the proposed monitoring system considers ZigBee to conform to industrial applicable standards and impacts cost effectiveness with real-time signal deployment.

\subsubsection{Gateway Application Layer Scheme}

In the industrial plants application, wireless sensor networks Gateway (GW) acts as the data sink for the sensor nodes and connect to the application platform through connections being it LAN (Ethernet), GSM, or others alike with acceptable Application Programming Interface (API). The significant element of any industrial WSNs configuration is to allow communication between the WSNs and API Gateway platform setup. The gateway can also be used to interface already existing wired sensor networks where required as inclusion. In multifaceted industrial application such as thermal condition monitoring, the gateway may use Ethernet and GSM interfaces with ZigBee to achieve the desired application concept. To enhance standardize the Gateway application interface, it then needs to be embedded with the API Gateway Abstraction Layer (GAL). The GAL allows interoperability of different WSNs with the application platform (Profibus-DP). GAL is compatible with ZigBee standard [56,62,77]. GAL can be directly incorporated as interface and its performance is in compliance with IEEE 802.15.4 [56]. The GAL functionality promotes the following features with appropriate data bus $[54,58,62,78]$ :

- ZigBee WSNs to compose nodes, which runs specific tasks for a local and wide network application functions.

- Low-layer interface to provide suitable network processor criteria usage to enhance the gateway to ZigBee platform.

- Formation of GAL core to promote the gateway state machine application of the system. 
- Forwarding of the WSNs application functionalities for implementation by the GAL core.

- Remote procedure call (RPC) layer to present the exposed system layer applications (local and remote) to operate in current implementation state. The RPC layer mechanism is used to make the process of executing code on a remote network or machine as simple and straightforward for local functions. Thus, enhance client call procedures as execution of returned functions. This makes the network server to simply define some routines that are to be assigned for export on ready.

- The local applications of running the application and to assign the WSNs platform the convenience of managing convergence.

The ZigBee gateway application layer proposes utility acceptable interface that is compatible with all processing signal connectivity of applications. To guarantee system signal real-time functioning, the gateway application layer embeds intelligence interrupt arbitration features, which neutralizes any delays the gateway interface might impact on the application signal on transmission. Thus, the working process of the application layer presents Profibus-DP as distributed peripheral to receive data from the ZigBee end nodes as slave and forwards command to the end field device for control actuation. This performs interface functioning of the ZigBee WSNs as coordinator. The Profibus-DP/ZigBee Gateway interlinks sensor nodes performance for control solutions from the GSMSMS alert notifications. The Profibus-DP is the first point of call to respond to the SMS alert notifications of the abnormal thermal condition through the gateway application layer [71-75,79].

LoRa interface of nodes at the gateway layer does not associate with specific gateway bus like been shown in the ZigBee configuration. Instead, data transmitted by nodes are typically received by multiple gateways concurrently, which could end up being received by all the gateways. The processing techniques concept applies the adaptive data rate (ADR) for its algorithm estimation of the coding rate (CR) and spreading factor (SF) for parameters under specific channel condition. Consequently, each gateway sends the received packet from the end node to the cloud-based network server through standard IP connections [65-73]. This is a challenge for the nodes managing interface as critical network assets, where LoRa/LoRaWAN submitted data experiences critical events scenarios beyond real-time schedules. Therefore, node duty-cycles ought to be set with the aim of reporting critical events concerning such peculiar conditions. This type of situation is a drawback of LoRa links in the event of signal collapse $[69,70]$. Moreover, the end-node configuration is a crucial aspect of the packet transmission purposes. Thus, any impossibility on the part of LoRa technology communications link to secure stringent duty-cycle during such critical conditions undermines network topology and deployment [68-70,80]. Figure 1 illustrates ZigBee gateway application layer interface.

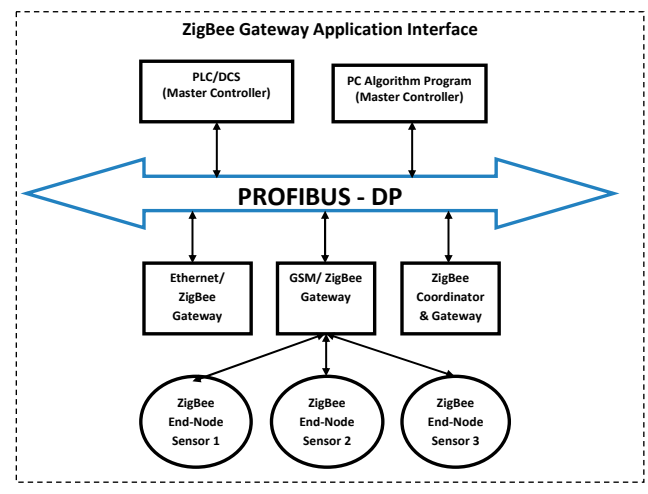

Figure 1. ZigBee gateway application interface.

An extensive literature review has been done on the emerging wireless communication links of low power consumption for wireless sensor network applications. The choice of reasonable and acceptable wireless communication link for the proposed design concept settled on the ZigBee/GSM WSNs for the design of monitoring and control solutions notification concept. We considered the pros and cons of wireless communication links for the application of the proposed design in rural and remote 
areas, thus choosing a communication link that signal deployment could be inimical to the system operation and further deteriorate performance will deviate from the design objective. Per the positive characteristics of ZigBee being adaptable in rural and remote areas as a matured communication link, the system opts for it, especially its real-time characteristics and gateway application interface layer for acceptance of other signal techniques.

\subsection{ZigBee and Wireless Sensor Networks Characteristics}

Progression in the development of the WSNs monitoring system to improve the performance of thermal conditions reduce the cost of thermal conditions monitoring scheme compared to the traditional wired-sensor network [21,63]. The ZigBee WSNs technology standards are of low-cost and self-coordinating [56]. It has excellent performance and seeks to overcome the economic aspect of industrial communication concerning capital and operational expenditures. The ZigBee WSNs sensor nodes can easily be added or removed from the local WSNs and the installation and maintenance costs are meagre. Additionally, it can be designed and configured at ease to operate directly from any terminal point with no restrictions or constraints for cable erection. ZigBee WSNs has reliable security configuration; different levels of data access can be assured and may not be compromised [56]. It allows possible local and remote signal feedbacks to be managed, employing suitable security actuation and data measurement transfers. The components of the ZigBee WSNs consist of three essential elements, namely the sensor nodes, radio communication with the router through star architecture or connected in a gateway mesh network that acts as an interface between WSNs, and the application platform $[21,61,77,81,82]$. In the industrial application, WSNs gateway acts as the data sink for the sensor nodes and connect to the application platform through connections of LAN or GSM.

Ideally, the technology works globally on $2.4 \mathrm{GHz}$ as unlicensed spread spectrum ISM band, however there are other ISM bands which ZigBee is compatible with [58,60,61]. ZigBee data rate characteristics range between $10 \mathrm{kbit} / \mathrm{s}$ and $250 \mathrm{kbit} / \mathrm{s}$ on the $2.4 \mathrm{GHz}$ band with a line of sight from $80 \mathrm{~m}$ to $1.5 \mathrm{~km}$ depending on the application configuration. The usual standard transmission line of sight range for most home applications has been about $100 \mathrm{~m}[58,60]$. Additionally, advancement in the ZigBee technology proposes various schemes to improve data rate and signal sensitivity with an increase in the line of sight ranges $[52,58,60,83,84]$. ZigBee has additional functioning characteristics regarding security, which determines the ability of the communication link to transmit or receive a signal with improved reliability against any form of interference. The ZigBee WSNs guarantee sensors node switching of wireless communication capabilities, which are compliant with ZigBee IEEE standard 802.15.4 and involves more sensors integration in the network where applicable. Sensors node do not communicate with each other directly, but through the network routers or the configuration of the on-board mesh switching, constituting the self-organized WSNs. Routers are always designed to be on and should always have active power sources $[21,54-57,77]$. Table 2, presents the features of ZigBee device being used in this paper.

Table 2. ZigBee Technology Characteristics.

\begin{tabular}{cc}
\hline \multicolumn{2}{c}{ ZigBee Technology (XBee-Pro ZigBee $\{$ S2C $\}$ ) } \\
\hline \multicolumn{2}{c}{ Overview: Higher Signal Strength, Less Power Consumption and Longer Range. } \\
\hline \multicolumn{2}{c}{ Charteristics } \\
\hline Frequency & $2.4 \mathrm{GHz}$ \\
Data rate & RF:250 kbps: Serial:1 Mbps \\
Maximum power transmit & $63 \mathrm{~mW}(18 \mathrm{dBm})$ \\
Max. current consumption (Transmitting) & $120 \mathrm{~mA}$ \\
Maximum receiver sensitivity & $-101 \mathrm{dBm}$ \\
Max. current consumption (Receiving) & $45 \mathrm{~mA}$ \\
Max. current consumption (sleep) & $<1 \mu \mathrm{A}$ \\
Maximum line of sight range & $3.2 \mathrm{~km}$ \\
Supply voltage & $2.7-3.6 \mathrm{VDC}$ \\
Operating temperature & $-40-+85^{\circ} \mathrm{C}$ \\
\hline
\end{tabular}




\subsection{Remedial Action for ZigBee Signal Challenges}

\subsubsection{Network Interference and Security}

The security of the communication link is the function of signal strength of the channel characteristics and determines the error correction methods deployed by the terminal equipment. Whereas the signal strength of the channel influences the signal-to-noise ratio (SNR), it is an assurance of the channel transmitted signal quality. It secures signal transmission quality concerning path loss, weather constraints, and the terminal equipment interferences. ZigBee WSNs configuration applies AES 128 data security integrity check and authentication for access control and data encryption. Using AES-128 security algorithm according to IEEE 802.15.4 standard ensures signal security [55-57]. It guarantees ZigBee reliability for collision avoidance and also reserves the bandwidth of the communication link. The data sent then avoids competition and conflicts. ZigBee operates on the instrumentation, scientific and medical (ISM) radio bands standard. The IEEE 802.15.4 standard specifies the Physical (PHY) and Medium Access Control (MAC) layers on such frequency bands. The spectrum bands include 902-928 MHz (USA), 868-870 MHz (Europe), $433.05-434.79 \mathrm{MHz}$ (the USA and Europe), and that of global band $2.400-2.4835 \mathrm{GHz}$ (worldwide) [58,60,85]. As it has been specified, the spectrums are enabled, either globally or nationally with the direct sequence spread spectrum (DSSS) interface using BPSK techniques for $868 \mathrm{MHz}$ and $915 \mathrm{MHz}$, and O-QPSK for $2.4 \mathrm{GHz}$ spectrum categories. Again, the convergence access methods enable network for carrier sense multiple access with collision avoidance (CSMA-CA). The IEEE 802.15.4 PHY standard supports the inclusion of receiver energy detection (ED) with link quality indication (LQI) and clear channel assessment (CCA). These are contention-based and contention-free channel access methods of supported standards employing 64-bit IEEE and 16-bit short addresses to enhance more nodes per network applications. The IEEE 802.15.4 MAC standard also operates network association and disassociation, with an optional super frame architectural of beacons for time synchronization. The synchronization guarantees time slot (GTS) mechanism with high priority communications [57-62,85,86].

The ISM spectrum bands accommodate applications including $\mathrm{Wi}-\mathrm{Fi}$, Bluetooth, and others. This shared spectrum band serves as a medium to exhibit interference to ZigBee especially from Wi-Fi. ZigBee and Wi-Fi coexistence challenges on the ISM frequency band is considered to be communication techniques issue on the same spectrum allocation. There are modalities envisaged to address such signal conflict. The techniques resolve to have interference avoidance and mitigation schemes including frequency co-existence on the same spectrum as discussed in [58,59,85-89]. ZigBee alliance supervises the ZigBee wireless technology, thus defining the network security and application layers relating to the IEEE 802.15.4 PHY and MAC layers standard. The MAC configuration safeguards data integrity by authenticating the source frame sequence and protects the source sending packets with enforcement encryption data unto the higher layers. It then adds frame sequence checks to identify transmission errors and process the data to the physical layer once the suitable channel access method is certified. The MAC techniques further control data transmission to avoid congestion and collisions particularly with similar topologies on the same spectrums where the collision of domain exists. Furthermore, MAC is similarly responsible for recompensing congestion and collisions by strategizing jam signal detection and negotiating retransmission channel and rate where applicable $[58,59,85,90,91]$. ZigBee has patterns to enable functioning schemes that allow application activities and performance throughput. They are categorized, as a full function device (FFD) and a reduced function device (RFD). Their functionality influences logical application decisions such as coordinator, router and the end device, with applications profile device techniques to assure reliable and secure wireless networks $[58,59,87,92]$. 


\subsubsection{Line of Sight and Signal Sensitivity}

Although ZigBee device may be challenged by the line of sight range and signal latency, there are options available to improve on its expected range. It can be improved with front end range amplifier as an extender, during the configuration setup assessment stage. The provision exists to be applied, for designs during link budget analysis. ZigBee device is applicable for all assignments including rural and remote areas on ISM frequency band. The choice of components should conform to specifications [59]. The installation configuration of ZigBee depends on the type of module in use as the development relies on the manufacturer circuit board specifications and the module compatibility. Factors such as structure obstacles, reflections, background noise, temperature, and humidity influence the throughput of the system performance. Datasheets of specification and configuration schemes are provided per the following references $[58,60,93-97]$ to achieve optimal range and signal sensitivity. Equation (2) supports the link budget assessment:

$$
d=\frac{\lambda}{4 \pi} \sqrt{\frac{P_{t} G_{t} G_{r}}{P_{r}}}
$$

where, $P_{r}=$ the receiver antenna power, $P_{t}=$ the transmitting power, $G_{r}=$ the gain of the receiver antenna, $G_{t}=$ the gain of the transmitter antenna, $d=$ the distance in meters, Lambda $(\lambda)=$ the wavelength carrier frequency of the ZigBee.

\subsection{Concept Development}

The LM35 temperature detector senses the thermal conditions from the respective assigned DERs points and converts into an electrical signal per the state conditions $[98,99]$. The Arduino ATMEGA328P microcontroller SIM900 with GSM/GPRS/XBee on the distribution field processes the signal that transmits to the GSM/XBee (receiver) at the DMS-DMU. The DMS-DMU is the data management unit of the distribution management system, where data is monitored and archived from the field measured thermal conditions. The GSM/XBee module/unit attached to the PC incorporates displaying information. Figure 2 is the block diagram of the concept design system.

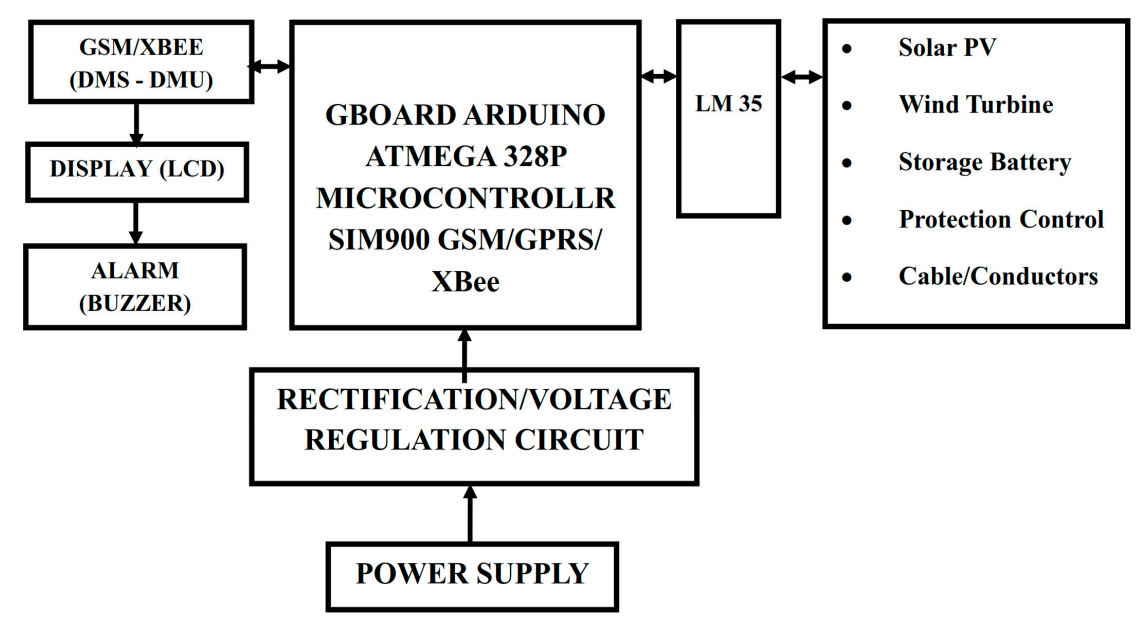

Figure 2. Block diagram of distributed energy resources (DERs) thermal condition monitor.

\section{Discussion of System Configuration and Performance Analysis}

\subsection{System Configuration Performance}

Figure 3 presents the design concept schematic diagram with the specifications as outlined in Table 2. The technology is considered more straightforward to install and reasonable in cost. ZigBee device works on radio frequency (RF) requiring a low to medium data rate, long battery lifetime, 
and low module power $[48,58,60,61,100,101]$. The architectural hardware design is classified, as the transmitter and receiver sections to work as a transceiver. The transmitter is considered as Arduino ATMEGA328P microcontroller with GSM/ZigBee and sensor nodes, whereas the receiver is at the DMS-DMU during the reporting stage. The design has sensors attached proximately to the components frames, or appropriate probes used where possible. The concept is developed to sense thermal behaviors of solar PV modules, wind turbine rotatory compartment, distribution line cables, protection control units, and storage batteries with inverters. The sensors and wireless communication link work in complement with the microcontroller to continuously monitor the conditions in both standard and abnormal status. The LM35 picks temperature signals after the initialization of the sensors with each node establishing a protocol link for real-time data exchange with ZigBee via the microcontroller. Each of the sensors continuously checks for the data in parity order on real-time [102-105]. At the receiving end, the other side of the ZigBee setup receives real-time data for decoding and analysis. The data received is an action controlled by the microcontroller and interface with gateway application layer. Limits are set and defined for sensor nodes configuration and performance according to threshold requirements. After checking the thermal condition thresholds status is acknowledged as normal or abnormal. If the data is out of the defined threshold range, status is abnormal. After the temperature measurement comparison, system issues an "Alert" action for an abnormal condition. SMS alert/notification sent and displayed on the LCD or a PC for details of the status information per configuration setup. The setup uses serial communication modem link to make voltage levels compatible with the microcontroller to receive the data serially, and to capture the real-time data on the LCD or PC display. Both the abnormal or normal data are shown at the field and the DMS-DMU.

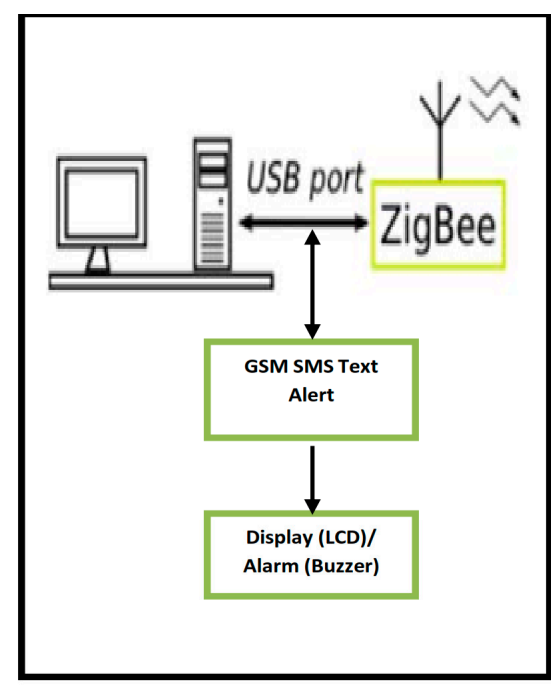

DMS - Data Management Unit

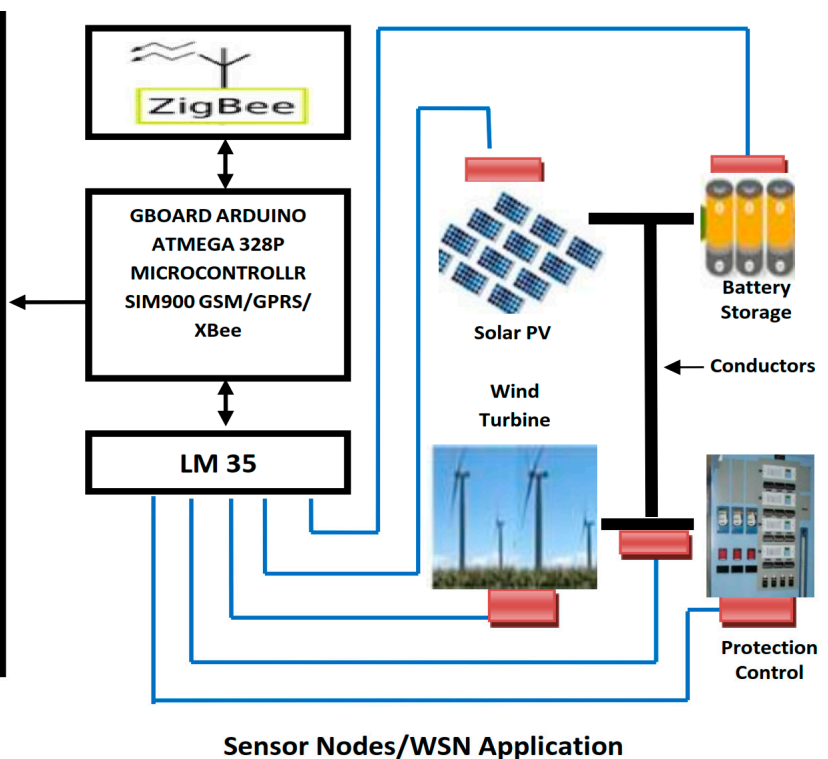

Sensor Nodes/WSN Application

Figure 3. System architectural illustration.

\subsection{System Algorithm Development}

The design has 10 algorithm implementation steps. The algorithm scheme coordinates the system state functions. The cycle scans state events between the DMS and WSNs nodes per the proposed time intervals to take account of overlapping activities due to temperature latency. The scan cycle does not interfere with system performance. Figure 4 shows the algorithm flow chart whiles Table 3, as explained by the function steps. 


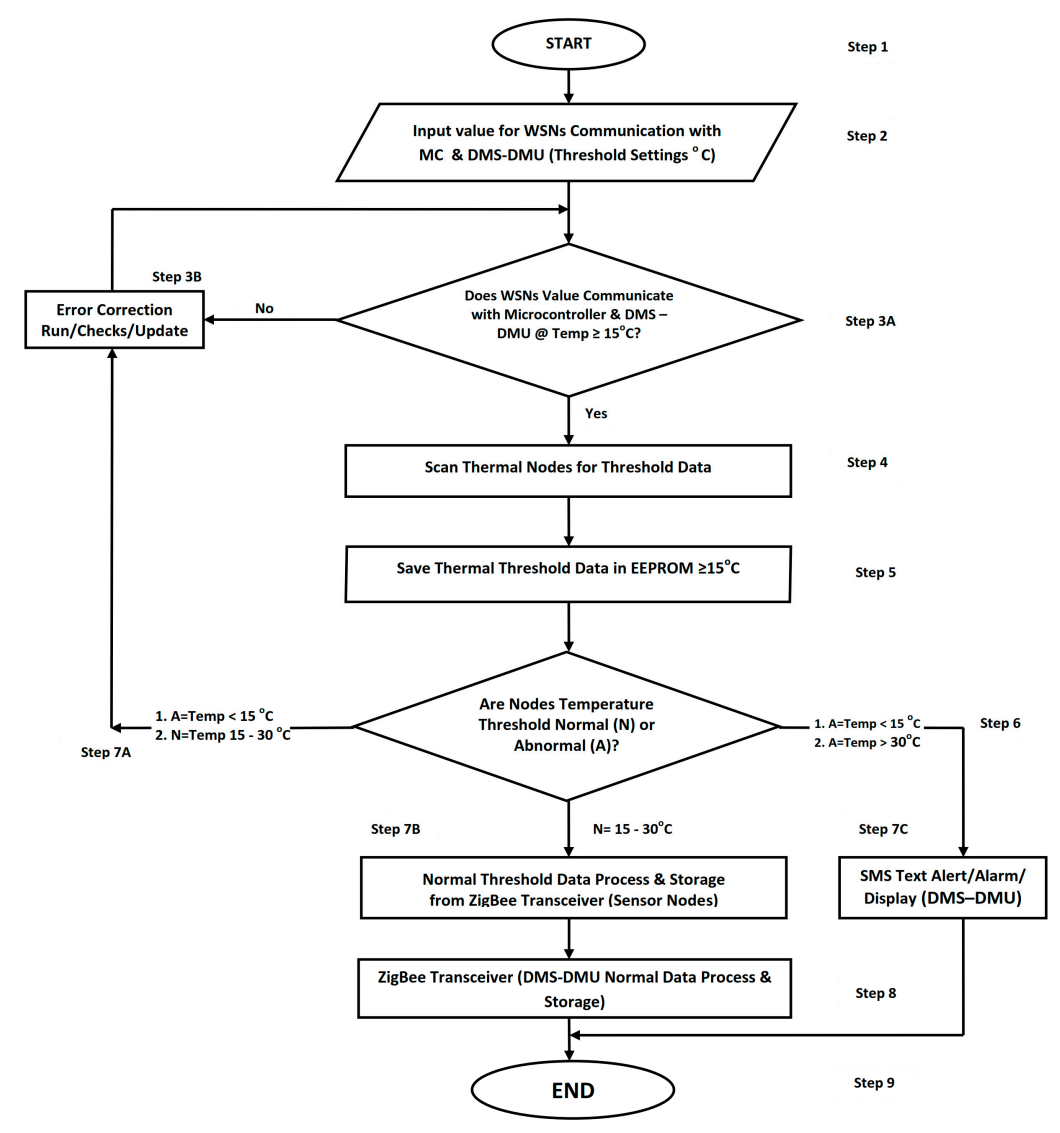

Figure 4. An algorithm flow chart.

Table 3. Algorithm implementation steps.

\begin{tabular}{|c|c|}
\hline Steps & Algorithm Functions \\
\hline Step 1 & The system is powered and regularized. \\
\hline Step 2 & $\begin{array}{l}\text { Checks and confirmation of WSNs nodes communication with microcontroller and } \\
\text { DMS-DMU system }\end{array}$ \\
\hline Step 3A & $\begin{array}{l}\text { Sensor nodes are initialized to communicate with other end devices via Arduino } \\
\text { ATMega328P Microcontroller (MC) ZigBee WSNs/GSM through gateway interface }\end{array}$ \\
\hline Step 3B & $\begin{array}{l}\text { Error/Correction/Checks. "NO" from step 3A, system updates and confirms operations } \\
\text { after error checked and cleared }\end{array}$ \\
\hline Step 4 \& 5 & $\begin{array}{l}\text { WSNs confirm threshold data for respective sensor nodes, which should not exceed the set } \\
\text { threshold values. The threshold values are saved in the EEPROM to avoid data loss should } \\
\text { there be an incipient power failure }\end{array}$ \\
\hline Step $6 \& 7 A$ & $\begin{array}{l}\text { Sensor nodes threshold data compares with the set threshold. If "Normal" (re-route to step } \\
\text { 3A for next cycle from 7A), and if "Abnormal" (process activates GSM SMS Text Alert to } \\
\text { send the message to DMS-DMU gateway interface for end field remedial action) through } \\
\text { step 7C }\end{array}$ \\
\hline Step 7B & Normal threshold data processed for storage through ZigBee transceiver for archives \\
\hline Step 7C & $\begin{array}{l}\text { Data exchange at DMS-DMU for "Abnormal" triggers SMS Text alert set from step } 6 \text { on } \\
\text { transitioning". Abnormal" SMS Alert/Display at DMS - DMU. The abnormal alert could be } \\
\text { configured for control solutions or remedial action. }\end{array}$ \\
\hline Step 8 & ZigBee transceiver at DMU Normal Data Process \& Storage and display) \\
\hline Step 9 & End of program \\
\hline
\end{tabular}


Algorithm Simulation and Analysis

The proposed design algorithm performs according to the temperature threshold settings of the DERs network components. The temperature values are configured for the measuring sensors. Profiles of temperature scenarios are transmitted to the DMS-DMU during the normal state for data storage. An SMS alert is also sent in times of system abnormal temperatures threshold. The primary function of the monitoring system is to coordinate and profile temperature thresholds. Moreover, the objective function is to trigger SMS alert activation for control solutions when there is out of range thresholds, for end field devices through gateway interface application layer at DMS-DMU. The simulation results provide a clear understanding of the ZigBee WSNs system configuration for the algorithm performance. Different operating temperature conditions were set to ascertain the algorithm performance response during the process according to the temperature threshold settings for verification and alert notifications for control and remedial solutions. Below are the configuration temperature settings of the design for simulations. The values are randomly selected.

1. Minimum set threshold operating temperature (temp) $=15^{\circ} \mathrm{C}$

2. Maximum set thresholds operating temperature (temp) $=30^{\circ} \mathrm{C}$

3. Normal operating temperature (temp) range $=15^{\circ} \mathrm{C}-30^{\circ} \mathrm{C}$

4. Critical alert minimum set temperature $($ temp $)=$ below $15^{\circ} \mathrm{C}$

5. Critical alert maximum set temperature (temp) $=$ above $30^{\circ} \mathrm{C}$

Algorithm simulation in Figure 5 shows $12{ }^{\circ} \mathrm{C}$ is configured in step 2 to run the algorithm test. The value is considered as the temperature below the minimum set threshold of $15^{\circ} \mathrm{C}$. In step $3 \mathrm{~A}$, the algorithm simulation responded with an error, which is regarded as default error input since it is below $15^{\circ} \mathrm{C}$. This condition was redirected to step 3B (Error correction/Run/Checks/Updates). The outcome of this simulation was successful according to the configuration criteria. Any temperature below the minimum set value for the iteration process would be considered an error and redirected for correction. The activity time elapsed is $6.302 \mathrm{~s}$.

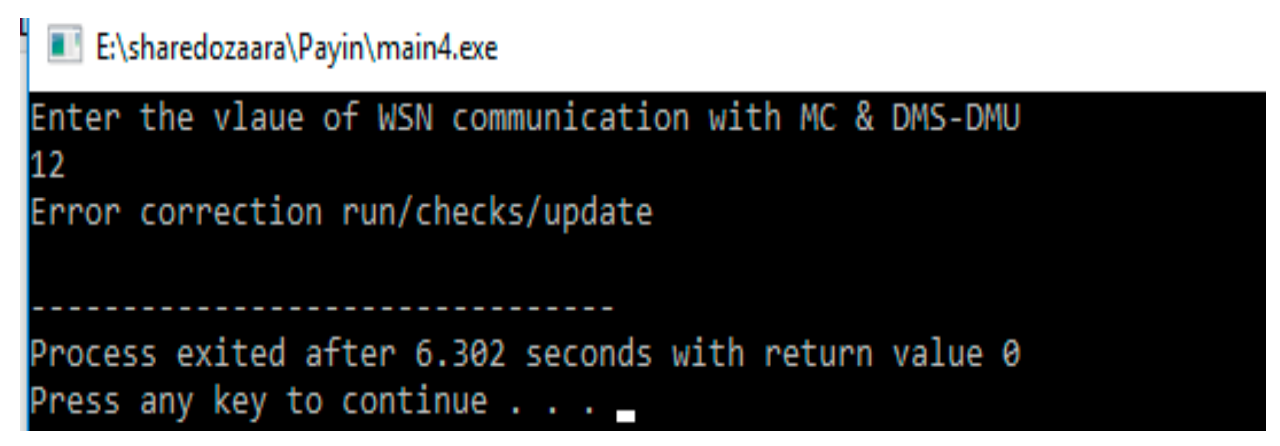

Figure 5. Default error input simulation.

In Figure $6,15^{\circ} \mathrm{C}$ was configured as a minimum input temperature set value to run the algorithm through steps 2 and $3 \mathrm{~A}$ successfully. However, during the process at steps 4 and 5, the temperature fell to $12{ }^{\circ} \mathrm{C}$ and $13{ }^{\circ} \mathrm{C}$, respectively. The EEPROM failed to save any of these as operating temperatures because the values were below the minimum set operating temperature threshold of $15^{\circ} \mathrm{C}$, although it has passed step 3A. The critical alert minimum constrained temperature is set below $15^{\circ} \mathrm{C}$. Therefore, the process is routed through step 7A for rescan of another cycle and 7C as abnormal system scenario which requires control remedial action through step $7 \mathrm{C}$. The temperature value is below the minimum operating range which cannot guarantee reliable performance. The condition could be attributed to weak solar PV irradiance during the night or in situations where irradiance will not be enough to generate needed power for the systems optimal performance. This condition then prompts SMS alerts for correction or proposes contingency control solution to remedy the situation through step 6 and 7C. 
It is also a possible indication to trigger an alert notification for battery low-temperature condition during extreme cold weather conditions for remedial actions. The elapsed time for this simulation was $22.11 \mathrm{~s}$.

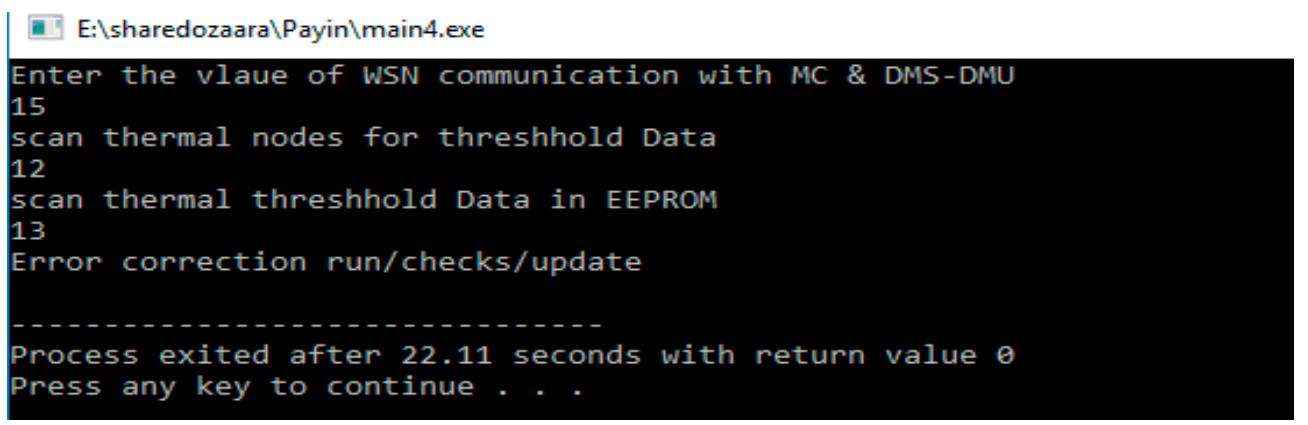

Figure 6. Critical alert minimum temperature below $15^{\circ} \mathrm{C}$.

Figure 7 shows the normal operating temperature simulation. The iterative temperature for the process was set at $45^{\circ} \mathrm{C}$ to allow system temperatures above normal operations. The temperature, however, fell to the reasonable operating threshold of $23^{\circ} \mathrm{C}$ and $29^{\circ} \mathrm{C}$ at steps 4 and 5 respectively. The EEPROM saved $29^{\circ} \mathrm{C}$ as normal temperature variable for the system at step 6 . Since it is within threshold settings, the temperature was confirmed normal operating threshold and stored through the ZigBee transceiver WSNs nodes step 7B and finally displayed and archived at the DMS-DMU for operations and maintenance purposes. The process elapsed time was $8.541 \mathrm{~s}$.

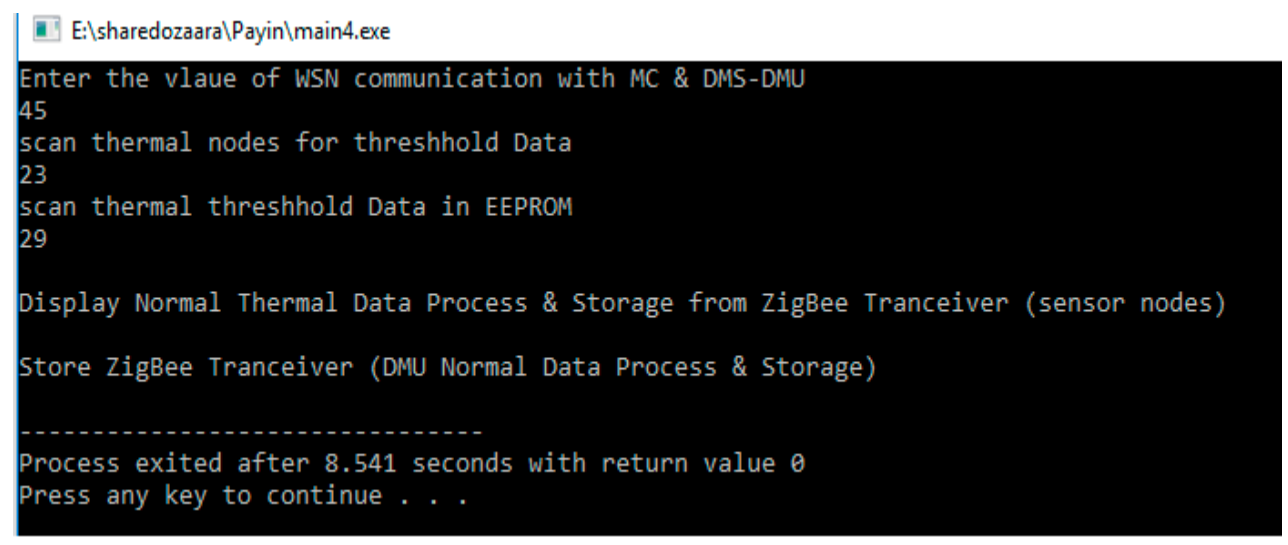

Figure 7. Normal operating temperature $\left(15-30^{\circ} \mathrm{C}\right)$.

The algorithm simulation in Figure 8 shows critical alert maximum constrained temperature above $30{ }^{\circ} \mathrm{C}$, with an iterative temperature value of $43^{\circ} \mathrm{C}$. During the process, the temperatures passed through steps 4 and 5 with values of $31^{\circ} \mathrm{C}$ and $43^{\circ} \mathrm{C}$, respectively. The temperatures indicate out of range threshold. The scenario is considered high-temperature thermal condition, hence rendering the system abnormal. The abnormal condition was routed through step 7C to trigger SMS alert for remedial action. The situation impedes optimal system operations and affects reliability. Control solutions could be set to activate remedial functions through this SMS notification. The scenario could be attributed to the high temperature on solar PV which could affect power generation. It could also be an indication of a high thermal impact on the transformer and protection control cooling system, which can ruin operations. The time elapsed for the simulation process was $21.47 \mathrm{~s}$. 


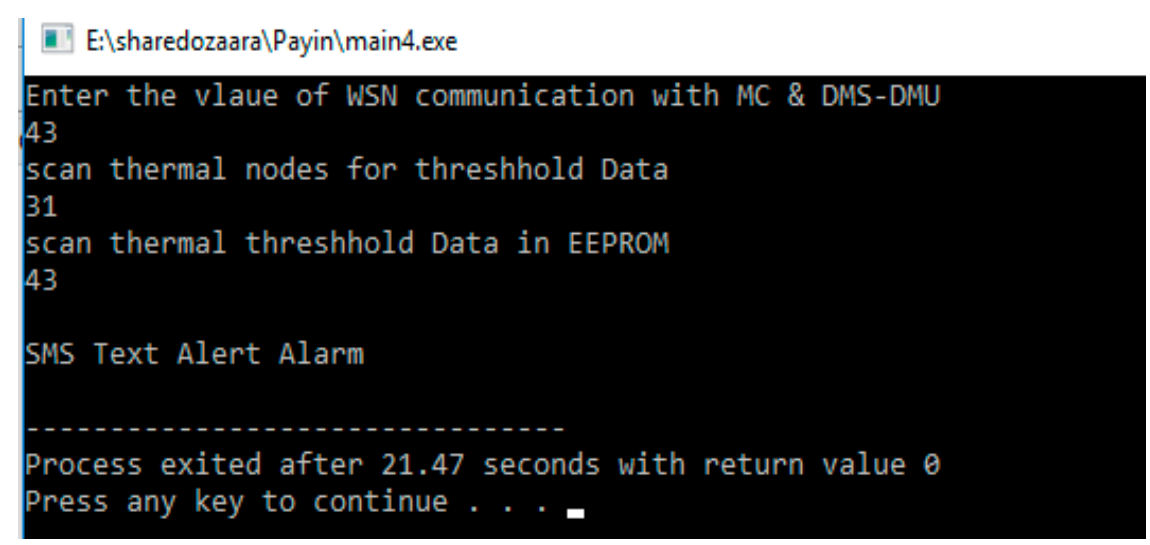

Figure 8. Critical alert maximum temperature above $30^{\circ} \mathrm{C}$.

\subsection{Design Concept Circuit Development and Simulation}

The Proteus design suite is a proprietary software tool, being used for electronic circuit design and automation. The software is used mainly for electrical and electronic designs to create schematics and electronic prints for circuit configurations. The schematics captured in the Proteus suite are for both the design phase development and component configurations analysis. The signal conditioning unit accepts the input signal from the sensors and gives conditioned output voltage to correspond with the range of each parameter. A constant voltage circuit source keeps component operating within a broad range of input voltage for the concept application. The liquid crystal display (LCD) presents information about the status of thermal condition behaviors. It helps to understand the condition characteristics when the alert notifications are issued. The LCD gives the alert interpretations, which further confirm or disprove false data sent.

The design circuit development analysis went through four stages of simulation exercises to confirm the design performance and also to verify alert notification responses. The configuration had the following elements for a cursory appearance on the Proteus suite: LCD monitor, ZigBee/ GSM modules, ATMEGA328P microcontroller Arduino unit, and the virtual terminal view of ZigBee/GSM including power supply source. There are also five thermal sensors with WSNs monitors on the plane. The thermal effects are configured with LM35 and identified as solar PV module $=\mathrm{T} 1$, battery storage with inverter $=\mathrm{T} 2$, wind turbine $=\mathrm{T} 3$, protection control unit $=\mathrm{T} 4$, and cables/conductors $=\mathrm{T} 5$.

The circuit operates according to the algorithm per the temperature threshold settings. In Figure 9, the diagram illustrates the normal operating temperatures for threshold from $15^{\circ} \mathrm{C}$ to $30^{\circ} \mathrm{C}$. The design displayed regular system operation performance in conformity with the configuration temperature settings within range. The LCD presented temperature data from $\mathrm{T} 1$ to $\mathrm{T} 5$. The indicated measurements according to the simulation were; $\mathrm{T} 1=16{ }^{\circ} \mathrm{C}, \mathrm{T} 2=19{ }^{\circ} \mathrm{C}, \mathrm{T} 3=22{ }^{\circ} \mathrm{C}, \mathrm{T} 4=26{ }^{\circ} \mathrm{C}$, and $\mathrm{T} 5=30{ }^{\circ} \mathrm{C}$. The measurements were both confirmed for the ZigBee transceiver WSNs nodes at the field for operations and DMS-DMU. The temperatures were indicated on the virtual terminal window of ZigBee/GSM module to confirm the system operations and data transmitted. The operating conditions had no SMS alerts because the temperatures were within the configuration range. The system stores the data for operation and maintenance purposes.

The system abnormal temperature conditions below the minimum operating threshold is simulated in Figure 10. The analysis illustrates out of range threshold scenario. The system measured temperatures below the minimum threshold of $15^{\circ} \mathrm{C}$. The measured temperatures are shown as; $\mathrm{T} 1=12{ }^{\circ} \mathrm{C}$, $\mathrm{T} 2=10^{\circ} \mathrm{C}, \mathrm{T} 3=14^{\circ} \mathrm{C}, \mathrm{T} 4=6{ }^{\circ} \mathrm{C}$, and $\mathrm{T} 5=13^{\circ} \mathrm{C}$. Again, the LCD monitor indicated condition status of "System Abnormal" beneath the displayed temperatures. The virtual terminal window for ZigBee/GSM module presents overall system temperature performance details with SMS alert activation commands through an assigned GSM link. All five thermal effect sensors displayed "Temp below threshold" to attest the abnormal system conditions. The alert notification commands could be configured as remedial control solutions for system actuation. 


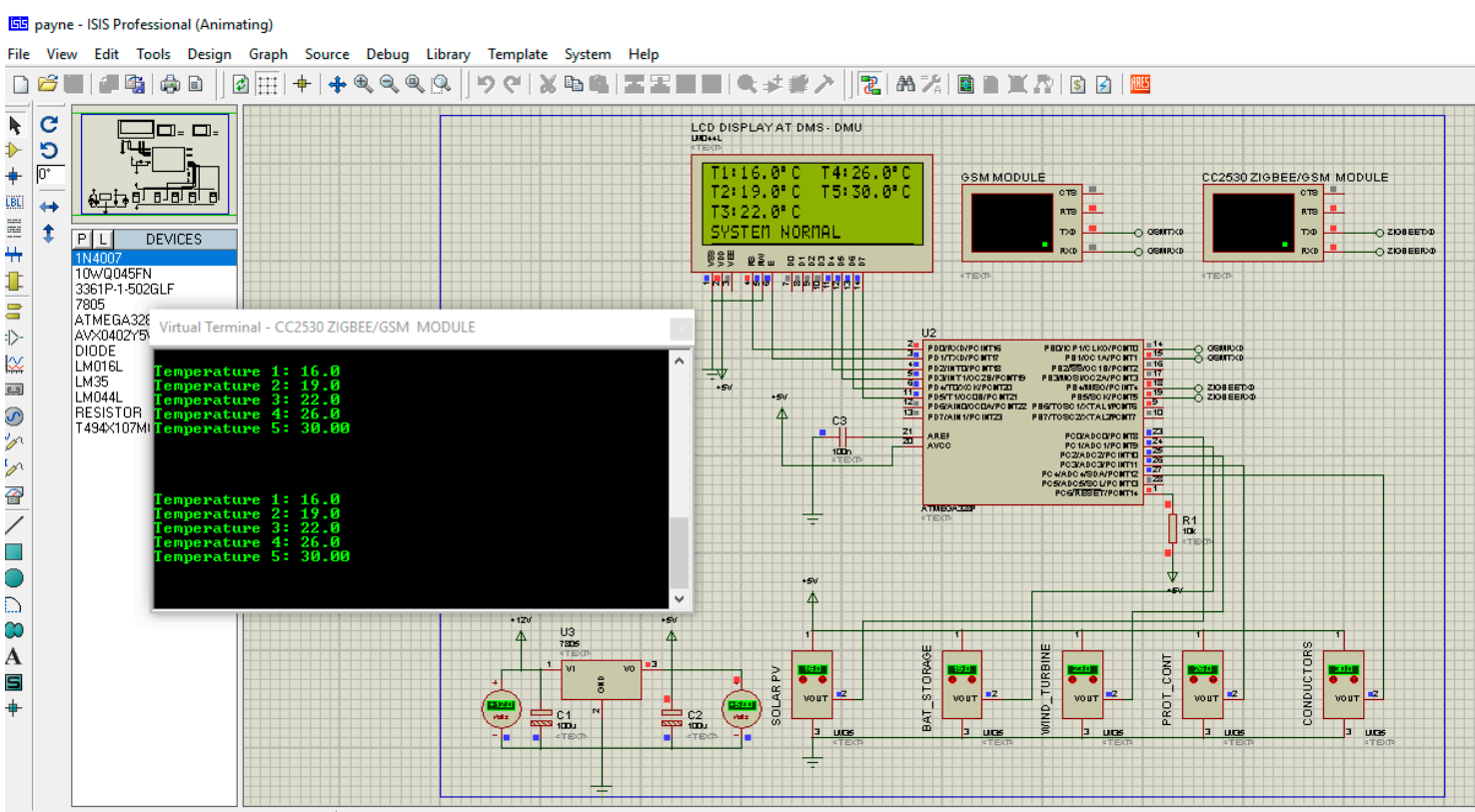

Figure 9. System normal operation temperatures $15^{\circ} \mathrm{C}$ to $30^{\circ} \mathrm{C}$.

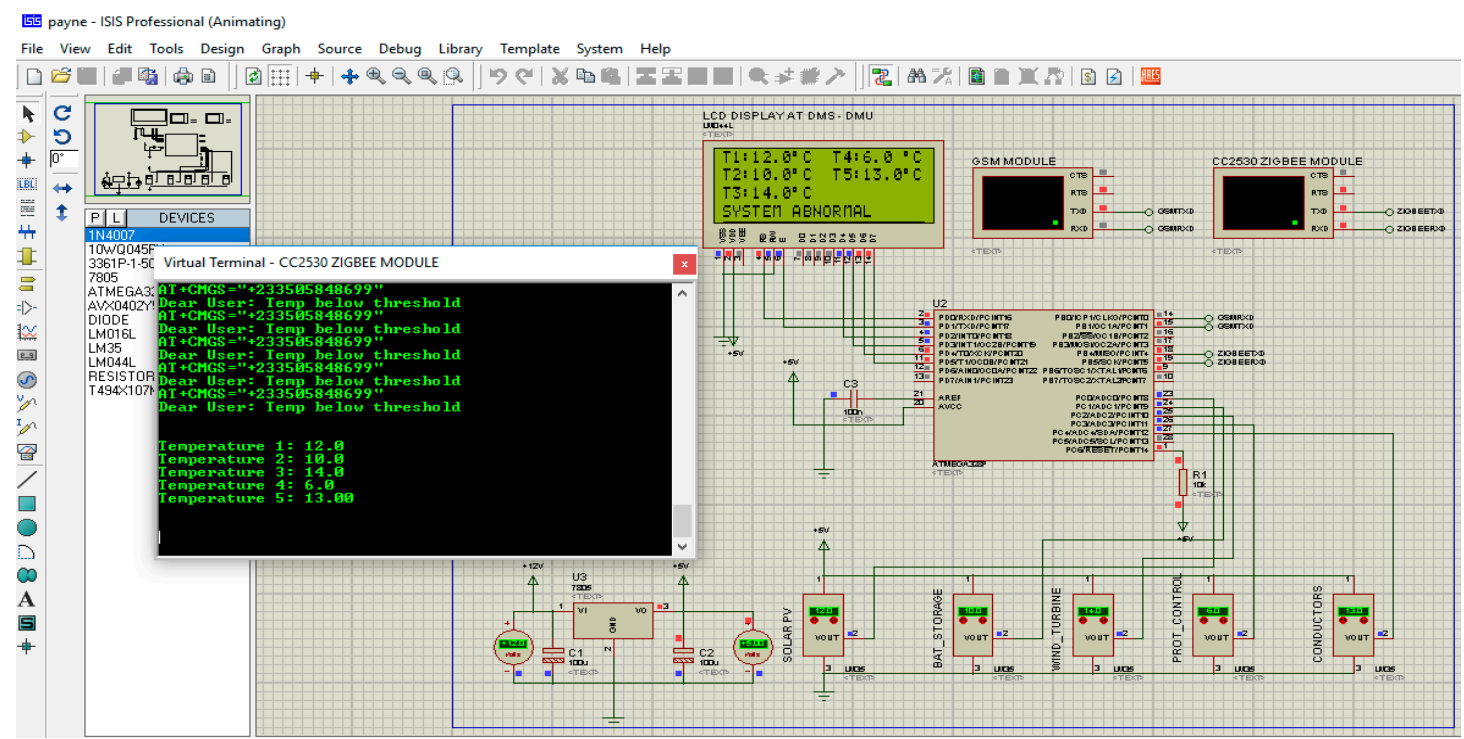

Figure 10. System abnormal condition below minimum settings.

Alternatively, Figure 11 presented an analysis of system abnormal condition for out of range temperatures above maximum operating threshold settings. The diagram depicts the temperature measured indications above $30^{\circ} \mathrm{C}$. The LCD monitor showed $31^{\circ} \mathrm{C}$ recordings for all the five thermal effect sensors as above maximum temperature threshold. The virtual terminal of the ZigBee/GSM module enumerated abnormal temperatures and triggered SMS alerts activation commands for remedial control solutions. The SMS alerts are shown as "Temp above threshold" with the respective transmitted temperatures itemized in the order of T1 to T5. Every temperature indicated $31^{\circ} \mathrm{C}$. It should be noted that SMS alert displays only when there is an abnormal temperature threshold to prompt remedial action functions. ZigBee normal operation does not use GSM SMS alert. 


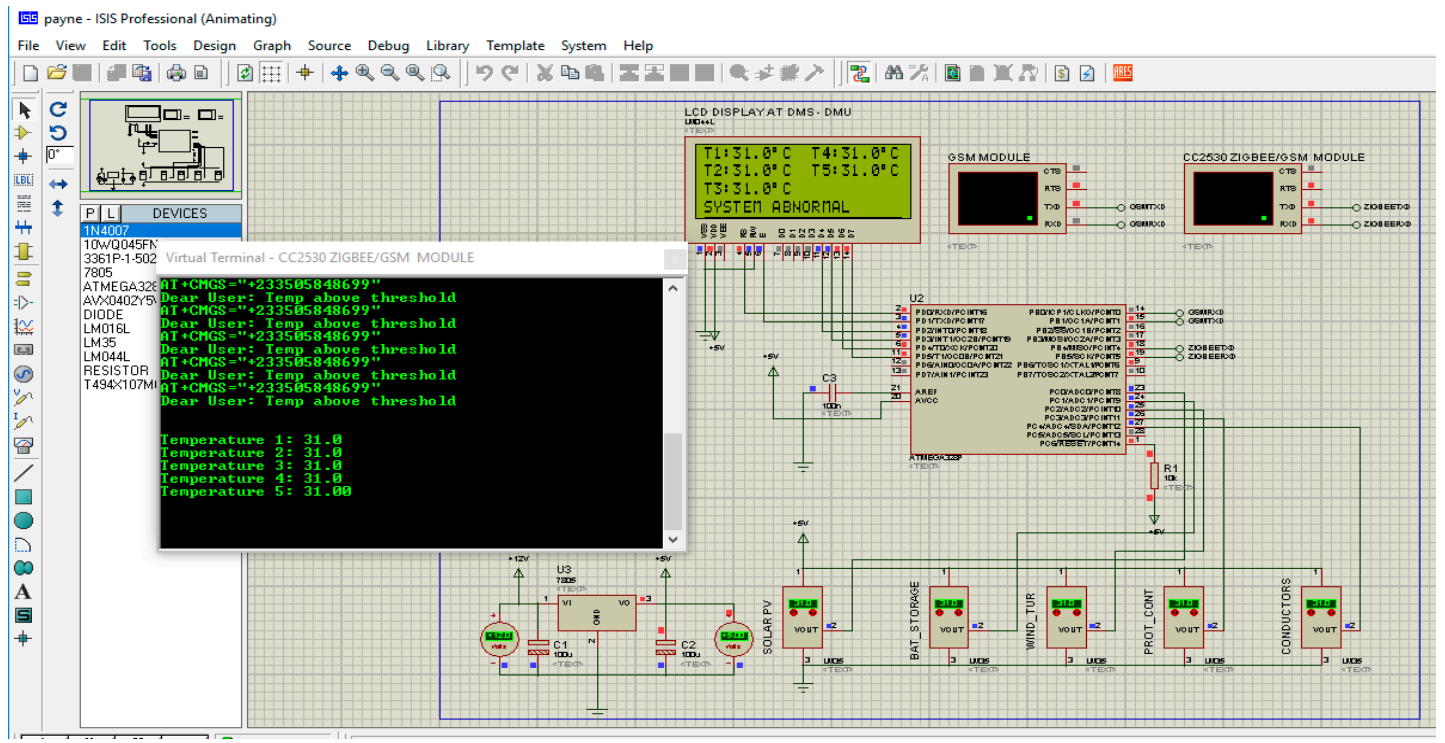

Figure 11. System abnormal condition above maximum settings.

To guarantee sensors individual performance, Figure 12 illustrates a simulation analysis of mixed scenarios for temperature measurements outcome. The mixed condition simulation comprises of normal range and the two other abnormal conditions temperature thresholds. The simulation proposes to ascertain operational scenarios where there could be a malfunction of some thermal conditions' sensors and monitors, while others could still be active and functions within their normal state and work discriminately. Although the LCD monitors system status as abnormal, temperature indications were of mixed conditions indicating individual measurements. The virtual terminal window of ZigBee/GSM module shows measured temperature details of specific sensor performance, and an SMS alert notifications command accordingly. Temperature measures from mixed condition simulation were; $\mathrm{T} 1=9{ }^{\circ} \mathrm{C}, \mathrm{T} 2=14{ }^{\circ} \mathrm{C}, \mathrm{T} 3=19{ }^{\circ} \mathrm{C}, \mathrm{T} 4=25^{\circ} \mathrm{C}$, and $\mathrm{T} 5=31^{\circ} \mathrm{C}$. The measurements confirmed the algorithm configuration's ability to operate independently in respect of system interdependence functioning scheme. Additionally, it guarantees the design performance scheme and SMS alerts command activation devoid of system configuration malfunctions.

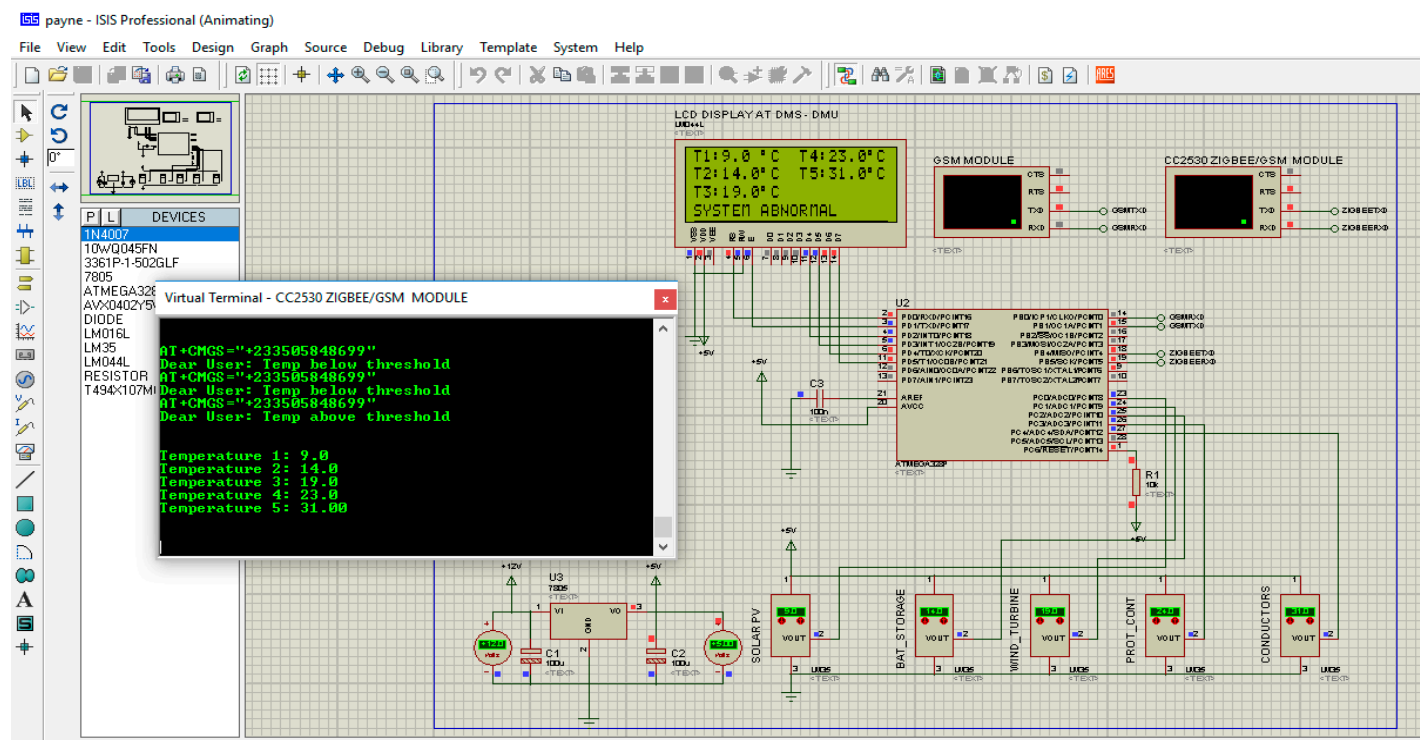

Figure 12. Mixed conditions of normal and abnormal ranges. 


\section{Conclusions}

The paper reviewed other wireless communication technologies link and their application in the industrial practice per WSNs. The choice of communication link was made considering the application of the design concept objective to be applicable in rural and remote areas. Review was done on the respective monitored components.

The design successfully performed in both algorithm and circuit development simulations. The analysis proved accurate selective performance, enabling active sensing and alert notifications through simulations. Although ZigBee devices have some challenges, remedial actions are prescribed to take charge per the references provided and the gateway abstraction layer (GAL) could be employed as an interface with other known long-range communication link for more coverage and integration of other sensors from different links. The ZigBee and GSM wireless sensor network incorporated in DERs integrated grid for thermal condition monitoring is compliant with the IEEE 802.15.4 standards. It confirms an emerging communication link for operations in the smart grid technology application. One of the achieved objective functions of this design concept is the ability of the system to send multiple individual constraints SMS alert notifications for control remedial solutions concurrently. The circuit development simulations confirm such possibility in Figures 10 and 11. These proved that the concept of algorithm was a success and algorithm development in emerging industrial sensor system holds relevance in design concepts. The design parameters can be updated, modified, and reconfigured to involve other aspects of the distribution network for additional functions from other links of circuits through the gateway interface application. Thus, it makes the concept a comprehensive and embracing remote condition monitoring tool. The analysis of the development was performed, through algorithm and circuit simulations. The concept is part of the present research work for the integration of DER works. The research seeks to involve a ZigBee signal communication link for monitoring and controlling of the grid for rural and remote distance.

Author Contributions: Conceptualization, E.K.P., L.S., Q.W., and L.W.; formal analysis, E.K.P. and L.S.; resources, L.S.; writing original draft, E.K.P., L.S., Q.W., and L.W.; review and editing, E.K.P., L.S., and L.W.; supervision, Q.W.; funding acquisition, Q.W.

Funding: This research was supported by National Natural Science Foundation of China grant number; No.51876083.

Acknowledgments: The National Natural Science Foundation of China is acknowledged for supporting this study. Again, the authors wish to appreciate and acknowledge the pains taking time of the reviewers for reading through the manuscript and the recommended corrections improvement.

Conflicts of Interest: The authors declare no conflict of interest.

\section{References}

1. Gungor, V.C.; Korkmaz, M.K. Wireless Link-Quality Estimation in Smart Grid Environments. Int. J. Distrib. Sensor Netw. 2012, 8, 214068. [CrossRef]

2. Wen, Y.J.; Agogino, A.M. Wireless Networked Lighting Systems for Optimizing Energy Savings and User Satisfaction. In Proceedings of the IEEE Wireless Hive Networks Conference, Austin, TX, USA, 7-8 August 2008.

3. Corsi, S. Voltage Control and Protection in Electrical Power Systems: From System Components to Wide-Area Control; Springer: London, UK, 2015.

4. Big Data Analytics, The Power and Energy Magazine, May/June 2018. Available online: www.iee.org/power (accessed on 19 June 2019).

5. Gers, J.M. Distribution System Analysis and Automation; IET: London, UK, 2014.

6. Masoum, M.A.S.; Fuchs, E.F. Power Quality in Power Systems and Electrical Machines, 2nd ed.; Academic Press Publications: London, UK, 2015.

7. Gabbar, H.A. Smart Energy Grid Engineering; Elsevier Inc.: London, UK, 2017. 
8. Katsioulis, V.; Karapidakis, E.; Hadjinicolaou, M.; Tsikalakis, A. Wireless Monitoring and Remote Control of PV Systems Based on the ZigBee Protocol. In Proceedings of the IFIP International Federation for Information Processing, IFIP AICT 349; Springer: Berlin, Germany, 2011; pp. 297-304.

9. IEEE-SA Standards Board. IEEE Standard 802.15.4-2015, IEEE Standard for Low-Rate Wireless Networks. Available online: https://standards.ieee.org/standard/802_15_4-2015.html (accessed on 19 June 2019).

10. Lu, J.; Zhao, X.; Yamada, S. Harmonic Balance Finite Element Method Applications in Nonlinear Electromagnetics and Power Systems; John Wiley \& Sons: Singapore, 2016.

11. Madeti, S.R.; Singh, S.N. Monitoring system for photovoltaic plants: A review. Renew. Sustain. Energy Rev. 2017, 67, 1180-1207. [CrossRef]

12. IEEE-SA Standards Board. IEEE Standard 519-1992, IEEE Recommended Practices and Requirements for Harmonic Control in Electrical Power. Available online: https://ieeexplore.ieee.org/document/210894/ similar\#similar (accessed on 19 June 2019).

13. Alonso, G.M.C.; Balenzategui, J.L. Estimation of photovoltaic module yearly temperature and performance based on nominal operation cell temperature calculations. Renew. Energy 2004, 29, 1997-2010.

14. Hsu, C.L. Constructing transmitting interface of running parameters of small-scaled wind-power electricity generator with WSN modules. Expert Syst. Appl. 2010, 37, 3893-3909. [CrossRef]

15. Payne, E.K.; Shulin, L.; Wang, Q.; Wu, L. Design Concept of Thermal Behaviour Condition Monitoring of Distributed Energy Resources Network System with ZigBee and GSM Technology in Remote and Rural Areas. In Proceedings of the 6th IEEE International Conference on Smart Energy Grid Engineering, UOIT, Oshawa, ON, Canada, 12-15 August 2018; pp. 298-302.

16. Gagliarducci, M.; Lampasi, D.A.; Podestà, L. GSM-based monitoring and control of photovoltaic power generation. Measurement 2007, 40, 314-321. [CrossRef]

17. Chu, D.; Lux, A. On-line monitoring of power transformers and components: A review of key parameters. In Proceedings of the Electrical Insulation Conference and Electrical Manufacturing and Coil Winding Conference (Cat. No.99CH37035), Cincinnati, OH, USA, 28 October 1999; Volume 26, pp. 669-675.

18. Tian, B.; Han, S.; Liu, L.; Khadem, S.; Parvin, S. Towards enhanced key management in multiphase ZigBee network architecture. Comput. Commun. 2012, 35, 579-588. [CrossRef]

19. Tavner, P.L.; Penman, J.; Sedding, H. Condition Monitoring of Rotating Electrical Machines; Institute of Engineering and Technology: London, UK, 2008; pp. 133-134.

20. Kronitiris, T.; Wasserrab, A.; Balzer, G. Weather-based loading of overhead lines consideration of conductor's heat capacity. In Proceedings of the International Symposium, 2010 Modern Electric Power Systems, Wroclaw, Poland, 20-22 September 2010.

21. Genova, F.; Bellifemine, F.; Gaspardone, M. Thermal and energy management system based on low-cost Wireless Sensor Network Technology, to monitor, control and optimize energy consumption in. In Proceedings of the 4th International Telecommunication-Energy Special Conference, Vienna, Austria, 10-13 May 2009.

22. Honing, N.; De Jong, E.; Bloemhof, G.; La Poutré, H. Thermal Behaviour of Low Voltage Cables in Smart Grid Related Environments. In Proceedings of the 2014 5th IEEE PES Innovative Smart Grid Technologies Europe (ISGT Europe), Istanbul, Turkey, 12-15 October 2014.

23. Ryszard, P. Engineering Thermodynamics of Thermal Radiation for Solar Power Utilization; McGraw-Hill: New York, NY, USA, 2010; pp. 365-371.

24. U.S. Department of Energy. A Vision for the Modern Grid; Office of Electricity Delivery and Energy Reliability, Dept of Energy: Washington, DC, USA, 2007.

25. Zahurul, S.; Mariun, N.; Grozescu, I.V.; Tsuyoshi, H.; Mitani, Y.; Othman, M.L.; Hizam, H.; Abidin, I.Z. Future strategic plan analysis for integrating distributed renewable generation to smart grid through wireless sensor network: Malaysia prospect. Renew. Sustain. Energy Rev. 2016, 53, 978-992. [CrossRef]

26. Hegazy, A.A. Comparative study of the performances of four photovoltaic thermal solar air collectors. Energy Convers. Manag. 2000, 41, 861-881.

27. Kaplani, E.; Kaplanis, S. Thermal modelling and experimental assessment of the dependence of PV module temperature on wind velocity and direction, module orientation and inclination. Sol. Energy 2014, 107, 443-460. [CrossRef]

28. Tiwari, A.; Sodha, M.S.; Chandra, A. Performance evaluation of photovoltaic thermal solar air collector for composite climate of India. Sol. Energy Mater. Sol. Cells 2007, 90, 175-189. [CrossRef] 
29. Tiwari, A.; Sodha, M.S. Parametric study of various configurations of hybrid PV thermal air collector: experimental validation of the theoretical model. Sol. Energy Mater. Sol. Cells 2007, 90, 9117-9128. [CrossRef]

30. Ji, C.; He, Z.; Wang, Q.; Xu, G.; Wang, S.; Xu, Z.; Ji, H. Effect of operating conditions on direct liquefaction of low-lipidmicroalgae in ethanol-water co-solvent for bio-oil production. Energy Convers. Manag. 2017, 141, 155-162. [CrossRef]

31. Wilson, R. Wind turbine aerodynamics. J. Ind. Aerodyn. 1980, 5, 357-372. [CrossRef]

32. Hameed, Z.; Hong, Y.S.; Cho, Y.M.; Ahn, S.H.; Song, C.K. Condition monitoring and fault detection of wind turbines and related algorithms: A review. Renew. Sustain. Energy Rev. 2009, 13, 1-39. [CrossRef]

33. Wang, Q.; Zhang, D.; Bai, J.; He, Z. Numerical simulation of catalysis combustion inside micro free-piston engine. Energy Convers. Manag. 2016, 113, 243-251. [CrossRef]

34. Adapa, R.; Douglass, D.A. Dynamic thermal ratings: Monitors and calculation methods. In Proceedings of the Inaugural IEEE PES 2005 Conference and Exposition in Africa, Durban, South Africa, 11-15 July 2005; pp. 163-167.

35. CIGRE WG 22.12. Thermal Behaviour of Overhead Conductors; Technical Brochure; Cigre: Brisbane, Australia, 2002; p. 207.

36. (Cable operation parameters); Olex Australia Pty Ltd. Aerial Conductor Catalogue. Available online: https://www.olex.com.au/Australasia/2012/OLC12641AerialCat.pdf (accessed on 19 June 2019).

37. Li, D.; He, Z.; Xuan, T.; Zhong, W.; Cao, J.; Wang, Q.; Wang, P. Simultaneous capture of liquid length of spray and flame lift-off length for second-generation biodiesel/diesel blended fuel in a constant volume combustion chamber. Fuel 2017, 189, 260-269. [CrossRef]

38. Berg, I.; LöbL, H.; Grossmann, S.; Golletz, F. Thermal behaviour of network components depending on outdoor weather conditions. In Proceedings of the 20th International Conference on Electricity Distribution, Prague, Czech Republic, 8-11 June 2009. Paper No. 0568.

39. Lelák, J.; Váry, M.; Packa, J.; Firický, E.; Skoršepová, T. STN EN 62271-202 Manual, High-Voltage Switchgear, and Control Gear: High Voltage/Low Voltage Prefabricated Substation Part 202; ERDF: The Slovak Republic, 2007.

40. Schaefer, M.; Feser, K. Thermal monitoring of large power transformers. In Proceedings of the PowerTech Budapest 99 Conference, Budapest, Hungary, 29 August-2 September 1999. [CrossRef]

41. Den Bossche, P.V.; Vergels, F.; Mierlo, J.V.; Matheys, J.; Van Autenboer, W. SUBAT: An assessment of sustainable battery technology. J. Power Sources 2006, 162, 913-919. [CrossRef]

42. Evans, A.; Strezov, V.; Evans, T.J. Assessment of utility energy storage options for increased renewable energy penetration. Renew. Sustain. Energy Rev. 2012, 16, 4141-4147. [CrossRef]

43. Leibfried, T. Online monitors keep transformers in service. IEEE Comput. Appl. Power 1998, 11, $36-42$. [CrossRef]

44. IEEE-SA Standards Board. IEEE Standard 1547-2018, IEEE Standard for Interconnection and Interoperability of Distributed Energy Resources with Associated Electric Power Systems Interfaces, IEEE. Available online: https://standards.ieee.org/standard/1547-2018.html (accessed on 19 June 2019).

45. Somani, N.A.; Patel, Y. Zigbee: A Low Power Wireless Technology for Industrial Application. Int. J. Control Theory Comput. Model. (IJCTCM) 2012, 2, 27-33. [CrossRef]

46. Mihajlov, B.; Bogdanoski, M. Overview and Analysis of the Performances of ZigBee based Wireless Sensor Networks. Int. J. Comput. Appl. 2011, 29, 28-35.

47. Moghe, R.; Lambert, F.C.; Divan, D. Smart stick sensors for the smart grid. IEEE Trans. Smart Grid 2012, 3, 241-252. [CrossRef]

48. ZigBee Datasheet specification. Available online: https://www.digi.com/pdf/ds_xbee_zigbee.pdf (accessed on 19 June 2019).

49. Wang, J.; Chen, J.; Xiong, X.; Lu, X.; Liao, Z.; Chen, X. Temperature safety analysis and backup protection scheme improvement for overhead transmission line in power oscillation condition. Electr. Power Syst. Res. 2019, 166, 88-98. [CrossRef]

50. Paulescu, M.; Paulescu, E.; Gravila, P. Solar Radiation Measurements, Weather Modeling, and Forecasting of PV Systems Operation; Springer: London, UK, 2013.

51. Fernández, E.F.; Almonacid, F.; Rodrigo, P.; Pérez-Higueras, P. Model for the prediction of the maximum power of a high concentrator photovoltaic module. Sol. Energy 2013, 97, 12-18. [CrossRef] 
52. Lohier, S.; Rachedi, A.; Salhi, I.; Livolant, E. Multichannel Access for Bandwidth Improvement in IEEE 802.15.4 Wireless Sensor Networks. In Proceedings of the IFIP/IEEE Wireless Days 2011 (IEEE WD'2011), Niagara Falls, ON, Canada, 10-12 October 2011.

53. Karapistoli, E.; Pavlidou, F.N.; Gragopoulos, I.; Tsetsinas, I. An Overview of the IEEE 802.15.4a Standard. IEEE Commun. Mag. 2010, 48, 47-53. [CrossRef]

54. Fairman, J.R.; Zimmerman, K.; Gregory, J.W.; Niemira, J.K. International Drive Distribution Automation and Protection. In Proceedings of the 55th Annual Georgia Tech Protective Relaying Conference, Atlanta, GA, USA, 2-4 May 2001.

55. Schweitzer, E.O., III; Finney, D.; Mynam, M.V. Applying Radio Communication in Distribution Generation Teleprotection schemes. In Proceedings of the 65th Annual Conference for Protective Relay Engineers, College Station, TX, USA, 2-5 April 2012.

56. IEEE. IEEE Standard Std 802.15.4 ${ }^{\mathrm{TM}}$-2015. Available online: https://ieeexplore.ieee.org/document/7460875 (accessed on 19 June 2019). [CrossRef]

57. Moxley, R.; Fodero, K. High-Speed Distribution Protection Made Easy: Communications-Assisted Protection Schemes for Distribution Applications. In Proceedings of the 31st Annual Western Protective Relay Conference, Spokane, WA, USA, 19-21 October 2004.

58. Batista, N.C.; Melício, R.; Matias, J.C.O.; Catalão, J.P.S. Photovoltaic and wind energy systems monitoring and building/home energy management using ZigBee devices within a smart grid. Energy 2013, 49, 306-315. [CrossRef]

59. Le, K.T. Designing a ZigBee ready IEEE 802.15.4- Compliant Radio Transceiver. Next Generation Wireless Magazine. pp. 42-50. Available online: www.rfdesign.com (accessed on 19 June 2019).

60. ZigBee Data Information. Available online: https://en.wikipedia.org/wiki/XBee (accessed on 19 June 2019).

61. Labiod, H.; Afifi, H.; Santis, C. Wi-Fi, Bluetooth, ZigBee, and WiMAX; Springer: Berlin, Germany, 2007.

62. Borean, C.; Pastrone, C. GAL: Gateway Abstraction Layer for fast application development in ZigBee Networks. In Proceedings of the 2nd European ZigBee Developers Conference - EuZDC 2008, Munich, Germany, 24-25 June 2008.

63. Benghanem, M. A low-cost wireless data acquisition system for weather station monitoring. Renew. Energy 2010, 35, 862-872. [CrossRef]

64. Collotta, M.; Salerno, V.M. A real-time network based on IEEE 802.15.4/ZigBee to control home automation environment. In Proceedings of the International forum "Modern Information Society Formation Problems, Perspectives, Innovation Approaches", St. Petersburg, Russia, 6-11 June 2010.

65. Arbab-Zavar, B.; Palacios-Garcia, E.J.; Vasquez, J.C.; Guerrero, J.M. Smart Inverters for Microgrid Applications: A Review. Energies 2019, 12, 840. [CrossRef]

66. Molina-Garcia, A.; Campelo, J.C.; Blanc, S.; Serrano, J.J.; Garcia-Sanchez, T.; Bueso, M.C. A Decentralized Wireless Solution to Monitor and Diagnose PV Solar Module Performance Based on Symmetrized-Shifted Gompertz Functions. Sensors 2015, 15, 18459-18479. [CrossRef]

67. Gungor, V.C.; Lu, B.; Hancke, G.P. Opportunities and challenges of wireless sensor networks in smart grid. IEEE Trans. Ind. Electron. 2010, 57, 3557-3564. [CrossRef]

68. Supriya, S.; Magheshwari, M.; Sree Udhyalakshmi, S.; Subhashini, R. Musthafa Smart grid technologies: Communication technologies and standards. Int. J. Appl. Eng. Res. 2015, 10, 16932-16941.

69. Mekki, K.; Bajic, E.; Chaxel, F.; Meyer, F. A comparative study of LPWAN technologies for large-scale IoT deployment. ICT Express 2019, 5, 1-7. [CrossRef]

70. LoraWAN Characteristics. Available online: https://www.link-labs.com/blog/what-is-lorawan (accessed on 19 June 2019).

71. Chen, F.; Talanis, T.; German, R.; Dressler, F. Real time Enabled IEEE 802.15.4 Sensor Networks in Industrial Automation. In Proceedings of the IEEE Symposium on Industrial Embedded Systems (SIES 2009), Lausanne, Switzerland, 8-10 July 2009; pp. 136-139.

72. Skendzic, V.; Guzma, A. Enhancing Power System Automation through the Use of Real-Time Ethernet. In Proceedings of the 2006 Power Systems Conference: Advanced Metering, Protection, Control, Communication, and Distributed Resources, Clemson, SC, USA, 14-17 March 2006.

73. Hancke, G.P.; Silva, B.; Hancke, G.P., Jr. The Role of Advanced Sensing in Smart Cities. Sensors 2013, 13, 393-425. [CrossRef] [PubMed] 
74. Dzung, P.Q.; Dao, N.D.; Nguyen, B.A.; Le, C.H.; Hong-Hee, L. Real-time communication network solution based on ZigBee and Ethernet for photovoltaic systems. In Proceedings of the 2014 IEEE 9th Conference on Industrial Electronics and Applications (ICIEA), Hangzhou, China, 9-11 June 2014; pp. 197-202.

75. Chaari, L.; Kamoun, L. IEEE 802.15.4/Zigbee Performance Analysis for Real Time Applications Using OMNET++ Simulator. In Advances in Wireless, Mobile Networks and Applications Communications, Computer and Information Science Vol. 154, Proceedings of the International Conferences WiMoA 2011 and ICCSEA 2011, Dubai, UAE, 25-27 May 2011; Springer: Berlin, Germany; pp. 54-68.

76. ZigBee Signal Characteristics. Available online: https://en.wikipedia.org/wiki/Zigbee\#Device_types_and_ operating_modes (accessed on 19 June 2019).

77. Jiang, N.; Zhu, Y. An Optimization Scheme in Wireless Temperature Measuring Sensor Network. In Proceedings of the 2015 IEEE 12th International Conference on Networking, Sensing and Control Howard Civil Service International House, Taipei, Taiwan, 9-11 April 2015; pp. 110-115.

78. Remote Procedure Calls. Available online: https://en.wikipedia.org/wiki/Remote_procedure_call (accessed on 19 June 2019).

79. Yang-ting, Y.; Hai-dong, L. Wireless Industrial Communication System Based on Profibus-DP and ZigBee. In Proceedings of the 11th International Conference on Computer Science \& Education (ICCSE 2016), Nagoya, Japan, 23-25 August 2016; pp. 666-669.

80. Persia, S.; Carciofi, C.; Faccioli, M. NB-IoT and LoRA connectivity analysis for M2M/IoT smart grids applications. In Proceedings of the AEIT International Annual Conference, Cagliari, Italy, 20-22 September 2017; pp. 1-6.

81. Mukaro, R.; Carelse, X.F. A microcontroller-based data acquisition system for solar radiation and environmental monitoring. IEEE Trans. Instrum. Meas. 1999, 48, 1232-1238. [CrossRef]

82. Harmah, D.J.; Payne, E.K. Telemedicine SMS-Based ECG Monitoring System. Int. J. Sci. Res. Publ. 2015, 5, 277-280.

83. Datasheet. Available online: https://www.digikey.com/en/producthighlight/d/digi-intl/world-of-digi-xbee (accessed on 19 June 2019).

84. Available online: https://www.digikey.com/en/articles/techzone/2011/may/unlicensed-915-mhz-bandfitsmany-applications-and-allows-higher-transmit-power (accessed on 19 June 2019).

85. Nadimi, E.S.; Jørgensen, R.N.; Blanes-Vidal, V.; Christensen, S. Monitoring and classifying animal behavior using ZigBee-based mobile ad hoc wireless sensor networks and artificial neural networks. Comput. Electron. Agric. 2012, 82, 44-54. [CrossRef]

86. Paredes-Parra, J.M.; Mateo-Aroca, A.; Silvente-Niñirola, G.; Bueso, M.C.; Molina-Garcia, A. PV Module Monitoring System Based on Low-Cost Solutions: Wireless Raspberry Application and Assessment. Energies 2018, 11, 3051. [CrossRef]

87. Shi, G.; Li, K. Signal Interference in Wi-Fi and ZigBee Networks; Springer International Publishing AG: Cham, Switzerland, 2017.

88. Sunil, J.; Priyanka, R. Enabling Coexistence of ZigBee and Wi-Fi. Commun. Appl. Electron. (CAE) 2015, 2, 28-34.

89. Barnabei, A.L.; Grassi, M.; Dallago, E.; Malcovati, P.; Finarelli, D.G.; Liberale, A.; Quaglia, F. A wireless irradiance-temperature-humidity sensor for photovoltaic plant monitoring applications. In Proceedings of the 2012 IEEE SENSORS, Taipei, Taiwan, 28-31 October 2012. [CrossRef]

90. Jaiswal, L.; Kaur, J.; Singh, G. Performance Analysis of Topological Variation in Personal Area Network using ZigBee Wireless Sensors I. JCST 2012, 3, 706-711.

91. Vlajic, N.; Stevanovic, D.; Spanogiannopoulos, G. Strategies for improving performance of IEEE 802.15.4 ZigBee WSNs with path constrained mobile sinks. Comput. Commun. 2011, 34, 743-757. [CrossRef]

92. Yuan, W.; Keshan, C.; Chao, X.; Hongjian, L. Design and Implementation for ZigBee Long distance Wireless Data Transmission System. In Proceedings of the 10th International Conference on Electronic Measurement \& Instruments (ICEMI), Chengdu, China, 16-19 August 2011.

93. Inam, F.; Sundar, S. Using CC2592 Front End with CC2530; Texas Instruments Application Report/Specification Manual, SWRA465A; August 2014, Revised July 2015; Texas Instruments: Dallas, TX, USA, 2015.

94. ZigBee CC2530; A True System-on-Chip Solution for 2.4-GHz, IEEE 802.15.4 and ZigBee Applications Data Specification Manual. Available online: www.ti.com/lit/an/swra465a/swra465a.pdf (accessed on 19 June 2019). 
95. ZigBee CC2592: A 2.4-GHz Range Extender Amplifier, Data Specification Manual (SWRS159). Available online: http://www.ti.com/jp/lit/ds/symlink/cc2592.pdf (accessed on 19 June 2019).

96. Skyworks. SKY65337-11: 2.4 GHz Transmit/Receive Front-End Module, Datasheet. Available online: www.skyworksinc.com (accessed on 19 June 2019).

97. Silicon Laboratories. EM260 ZigBee/802.15.4 Network Processor, Datasheet. Available online: www.silabs. com (accessed on 19 June 2019).

98. Pierce, L.W. An investigation of the thermal performance of oil filled transformer winding. IEEE Trans. Power Deliv. 1992, 7, 1347-1358. [CrossRef]

99. Lachman, M.F.; Griffin, J.; Walter, P.; Wilson, A. Real-time dynamic loading and thermal diagnostic of power transformers. IEEE Trans. Power Deliv. 2003, 18, 142-148. [CrossRef]

100. Payne, E.K.; Harmah, D.J. Multi-parametric Telemetry Patient Monitoring System. Int. J. Sci. Res. Publ. 2015, 5, 272-276.

101. Kai, C.; Zhanfeng, Y.; Xiong, C. Model predictive control security economic dispatch model considering transmission line thermal inertia effect. Trans. CES 2018, 33, 1875-1883.

102. Uttamchandani, D. Handbook of MEMS for Wireless and Mobile Applications; Woodhead Publishing Limited: New Delhi, India, 2013.

103. Nihtianov, S.; Luque, A. Smart Sensors and MEMS Intelligent Devices and Microsystems for Industrial Applications; Woodhead Publishing Limited: New Delhi, India, 2014.

104. Olukan, T.A.; Emziane, M. A Comparative Analysis of PV Module Temperature Models, 6th International Conference on Sustainability in Energy and Buildings, SEB-14. Energy Procedia 2014, 62, 694-703. [CrossRef]

105. Greenwood, D.M.; Gentle, J.P.; Myers, K.S.; Davison, P.J.; West, I.J.; Bush, J.W.; Ingram, G.L.; Troffaes, M.C. A comparison of real-time thermal rating systems in the U.S. and the U.K. IEEE Trans. Power Deliv. 2014, 29, 1849-1858. [CrossRef]

(C) 2019 by the authors. Licensee MDPI, Basel, Switzerland. This article is an open access article distributed under the terms and conditions of the Creative Commons Attribution (CC BY) license (http://creativecommons.org/licenses/by/4.0/). 